NBER WORKING PAPER SERIES

\title{
OPTIMAL MONETARY POLICY
}

\author{
Aubhik Khan \\ Robert G. King \\ Alexander L. Wolman \\ Working Paper 9402 \\ http://www.nber.org/papers/w9402
NATIONAL BUREAU OF ECONOMIC RESEARCH
1050 Massachusetts Avenue
Cambridge, MA 02138 \\ December 2002
}

The authors thank Bernardino Adao, Orazio Attanasio, Isabel Correia, Bill Dupor, Chris Erceg, Steve Meyer, Pedro Teles, Julia Thomas and Michael Woodford for useful conversations and comments. In addition, we have benefited from presentations at the June 2000 Banco de Portugal Conference on Monetary Economics; the NBER Summer Institute, the Society for Economic Dynamics meeting, the Federal Reserve System Committee, Rutgers University, and the University of Western Ontario. The views expressed here are the authors' and not necessarily those of the Federal Reserve Banks of Philadelphia or Richmond, the Federal Reserve System or the National Bureau of Economic Research.

(C) 2002 by Aubhik Khan, Robert G. King, and Alexander L. Wolman. All rights reserved. Short sections of text not to exceed two paragraphs, may be quoted without explicit permission provided that full credit including, (C) notice, is given to the source. 
Optimal Monetary Policy

Aubhik Khan, Robert G. King, and Alexander L. Wolman

NBER Working Paper No. 9402

December 2002

JEL No. E5

\begin{abstract}
Optimal monetary policy maximizes the welfare of a representative agent, given frictions in the economic environment. Constructing a model with two sets of frictions -- costly price adjustment by imperfectly competitive firms and costly exchange of wealth for goods -- we find optimal monetary policy is governed by two familiar principles. First, the average level of the nominal interest rate should be sufficiently low, as suggested by Milton Friedman, that there should be deflation on average. Yet, the Keynesian frictions imply that the optimal nominal interest rate is positive. Second, as various shocks occur to the real and monetary sectors, the price level should be largely stabilized, as suggested by Irving Fisher, albeit around a deflationary trend path. Since expected inflation is roughly constant through time, the nominal interest rate must therefore vary with the Fisherian determinants of the real interest rate. Although the monetary authority has substantial leverage over real activity in our model economy, it chooses real allocations that closely resemble those which would occur if prices were flexible. In our benchmark model, there is some tendency for the monetary authority to smooth nominal and real interest rates.
\end{abstract}

$\begin{array}{ll}\text { Aubhik Khan } & \text { Robert G. King } \\ \text { Research Department } & \text { Department of Economics } \\ \text { Federal Reserve Bank } & \text { Boston University } \\ \text { of Phildelphia } & \text { 270 Bay State Road } \\ \text { 10 Independence Mall } & \text { Boston, MA 02215 } \\ \text { Philadelphia, PA 19106 } & \text { and NBER } \\ \text { aubhik.khan@phil.frb.org } & \text { rking@bu.edu }\end{array}$

Aubhik Khan

Research Department

Federal Reserve Bank

of Phildelphia

Philadelphia, PA 19106

rking@bu.edu

\author{
Alexander L. Wolman \\ Research Department \\ Federal Reserve Bank \\ of Richmond \\ P.O. Box 27622 \\ Richmond, VA 23261 \\ alexander.wolman@rich.frb.org
}




\section{Introduction}

Three distinct intellectual traditions are relevant to the analysis of how optimal monetary policy can and should regulate the behavior of the nominal interest rate, output and the price level.

The Fisherian view: Early in this century, Irving Fisher [1923,1911] argued that the business cycle was "largely a dance of the dollar" and called for stabilization of the price level, which he regarded as the central task of the monetary authority. Coupled with his analysis of the determination of the real interest rate [1930] and the nominal interest rate [1896], the Fisherian prescription implied that the nominal interest rate would fluctuate with those variations in real activity which occur when the price level is stable.

The Keynesian view: Stressing that the market-generated level of output could be inefficient, Keynes [1936] called for stabilization of real economic activity by fiscal and monetary authorities. Such stabilization policy typically mandated substantial variation in the nominal interest rate when shocks, particularly those to aggregate demand, buffeted the economic system. Prices were viewed as relatively sticky and little importance was attached to the path of the price level.

The Friedman view: Evaluating monetary policy in a long-run context with fully flexible prices, Friedman [1969] found that an application of a standard microeconomic principle of policy analysis - that social and private cost should be equated indicated that the nominal interest rate should be approximately zero. Later authors used the same reasoning to conclude that the nominal interest rate should not vary through time in response to real and nominal disturbances, working within flexible price models of business fluctuations. ${ }^{1}$

There are clear tensions between these three traditions if real forces produce expected changes in output growth that affect the real interest rate. If the price level is constant, then the nominal interest rate must mirror the real interest rate, violating Friedman's rule. If the nominal interest rate is constant, as Friedman's rule suggests, then there must be expected inflation or deflation to accommodate the movement in the real rate, and thus Fisher's prescription cannot be maintained. The variation in inflation and nominal interest rates generally implied by Keynesian stabilization conflicts with both the Friedman and Fisherian views.

We construct a model economy that honors each of these intellectual traditions and study the nature of optimal monetary policy. There are Keynesian features to the economy: output is inefficiently low because firms have market power and fluctuations reflect the fact that all prices cannot be frictionlessly adjusted. However, as in the New Keynesian research on price stickiness that begins with Taylor [1980], firms are forward-looking in their price setting and this has dramatic implications for the design of optimal monetary policy. In our economy, there are also costs of converting wealth into consumption. These costs can be mitigated by the use of money, so that there are

\footnotetext{
${ }^{1}$ Chari and Kehoe [1999] survey these developments.
} 
social benefits to low nominal interest rates as in Friedman's analysis. The behavior of real and nominal interest rates in our economy is governed by Fisherian principles.

Following Ramsey [1927] and Lucas and Stokey [1983], we determine the allocation of resources which maximizes welfare of a representative agent given the resource constraints of the economy and additional constraints that capture the fact that the resource allocation must be implemented in a decentralized private economy. The staggered nature of price-setting in our economy means that there are many implementation constraints that must be respected. ${ }^{2}$ We assume that there is full commitment on the part of a social planner for the purpose of determining these allocations and find that two familiar principles govern monetary policy in our economy.

1. The Friedman prescription for deflation. The average level of the nominal interest rate should be sufficiently low that there should be deflation on average, as suggested by Milton Friedman. Yet, the Keynesian frictions generally imply that there should be a positive nominal interest rate.

2. The Fisherian prescription for eliminating price-level surprises. As shocks occur to the real and monetary sectors, the price level should be largely stabilized, as suggested by Irving Fisher, albeit around a deflationary trend path. (In modern language, there is only a small "base drift" for the price level path). Since expected inflation is relatively constant through time, the nominal interest rate must therefore vary with the Fisherian determinants of the real interest rate. However, there is some tendency for nominal and real interest rate smoothing relative to the outcomes in a flexible price economy.

By contrast, we find less support for Keynesian stabilization policy. Although the monetary authority has substantial leverage over real activity in our model economy, it chooses allocations that closely resemble those which would occur if prices were flexible. When departures from this flexible price benchmark occur under optimal policy, they are not always in the traditional direction: in one example, a monetary authority facing a high level of government demand chooses to contract private consumption relative to the flexible price outcome, rather than stimulating it.

The organization of the paper is as follows. In section 2, we outline the main features of our economic model and define a recursive imperfectly competitive equilibrium. In section 3, we describe the nature of the general optimal policy problem that we solve, which involves a number of forward-looking constraints. We outline how to treat this policy problem in an explicitly recursive form. Our analysis thus exemplifies a powerful recursive methodology for analyzing optimal monetary policy in richer models that could include capital formation, state dependent pricing and other frictions such as efficiency wages or search. In section 4, we identify four distortions

\footnotetext{
${ }^{2}$ Ireland [1996], Goodfriend and King [2001] and Adao, Correia and Teles [2001] use a similar approach to study models with pre-set prices. These models contain only one or two implementation constraints.
} 
present in our economic model, which are summary statistics for how its behavior can differ from a fully competitive, nonmonetary business cycle model. In section 5 , we discuss calibration of a quantitative version of our model, including estimation of a money demand function.

In section 6 , we discuss the results which lead to the first principle for monetary policy: the nominal interest rate should be set at an average level that implies deflation, but it should be positive. We show how this steady-state rate of deflation depends on various structural features of the economy including the costs of transacting with credit, which give rise to money demand, and the degree of price-stickiness. ${ }^{3}$ In our benchmark calibration, which is based on an estimated money demand function using post-1958 observations, the extent of this deflation is relatively small, about $.75 \%$. It is larger (about $2.3 \%$ ) if we use estimates of money demand based also on observations from 1948-1958; this longer sample includes intervals when interest rates and velocity were both low, which Lucas [2000] argues are important for estimation of the demand for money and the calculation of associated welfare cost measures. In addition, a smaller degree of market power or less price stickiness make for a larger deflation under optimal policy.

In section 7, we describe the near-steady state dynamics of the model under optimal policy. Looking across a battery of specifications, we find that these dynamics display only minuscule variation in the price level. Thus, we document that there is a robustness to the Fisherian conclusion in King and Wolman [1999], which is that the price level should not vary greatly in response to a range of shocks under optimal policy. In fact, the greatest price level variation that we find involves less than a $0.5 \%$ change in the price level over twenty quarters, in response to a productivity shock which brings about a temporary but large deviation of output from trend, in the sense that the cumulative output deviation is more than $10 \%$ over the twenty quarters. Across a range of experiments, output under optimal policy closely resembles output which would occur if all prices were flexible and monetary distortions were absent. We refer to the flexible price, nonmonetary model as our underlying real business cycle framework. Although the deviations of quantities under optimal policy from their real business cycle counterparts are small, because these deviations are temporary, they give rise to larger departures of real interest rates from those in the RBC solution. We relate the nature of these departures to the nature of constraints on the monetary authority's policy problem. Section 8 concludes.

\section{The model}

The model incorporates elements from two important strands of macroeconomic research. First, money is a means of economizing on the use of costly alternative media

\footnotetext{
${ }^{3}$ By the steady state, we mean the point to which the economy converges under optimal policy if there is no uncertainty.
} 
as in the classic analyses of Baumol [1952] and Tobin [1956]. ${ }^{4}$ Second, firms are imperfect competitors facing infrequent opportunities for price adjustment as in much recent New Keynesian research beginning with Taylor [1980] and Calvo [1983]. To facilitate the presentation of these mechanisms, we view the private sector as divided into three groups of agents. First, there are households which buy final consumption goods and supply factors of production. These households also trade in financial markets for assets, including a credit market, and acquire cash balances which can be exchanged for goods. Second, there are retailers, which sell final consumption goods to households and buy intermediate products from firms. Retailers can costlessly adjust prices. ${ }^{5}$ Third, there are producers, who create the intermediate products that retailers use to produce final consumption goods. These firms have market power and face only infrequent opportunities to adjust prices.

The two sources of uncertainty are the level of total factor productivity, $a$, and the level of real government purchases, $g$, which is assumed to be financed with lump-sum taxes. These variables depend on an exogenous state variable $\varsigma$, which evolves over time as a Markov process, with the transition probability denoted $\Upsilon(\varsigma, \cdot)$. That is, if the current state is $\varsigma$ then the probability of the future state being in a given set of states $B$ is $\Upsilon(\underline{\varsigma}, B)=\operatorname{Pr}\left\{\varsigma^{\prime} \in B \mid \varsigma=\underline{\varsigma}\right\}$. We thus write total factor productivity as $a(\varsigma)$ and real government spending as $g(\varsigma)$.

In this section, we describe a recursive equilibrium, with households and firms solving dynamic optimization problems given a fixed, but potentially complicated, rule for monetary policy that allows it to respond to all of the relevant state variables of the economy, which are of three forms. Ignoring initially the behavior of the monetary authority, the model identifies two sets of state variables. First, there are the exogenous state variables just discussed. Second, since some prices are sticky, predetermined prices are part of the relevant history of the economy. These variables, $s$, evolve through time according to a multivalent function $\Gamma$ where $s^{\prime}=\Gamma\left(s, p_{0}, \pi\right)$, with $p_{0}$ and $\pi$ being endogenous variables further described below. We allow the monetary authority to respond to $\varsigma$ and $s$, but also to a third set of state variables $\phi$, which evolves according to $\phi^{\prime}=\Phi(\varsigma, s, \phi)$. In a recursive equilibrium, $p_{0}$ and $\pi$ are functions of the monetary rule, so that the states $s$ evolve according to $s^{\prime}=$ $\Gamma\left(s, p_{0}(\varsigma, s, \phi), \pi(\varsigma, s, \phi)\right)$; we will sometimes write this as $s^{\prime}=\Gamma(s, \phi, \varsigma)$. Hence, there is a vector of state variables $\sigma=(s, \phi, \varsigma)$ that is relevant for agents, resulting from the stochastic nature of productivity and government spending; from the endogenous dynamics due to sticky prices; and, potentially, from the dynamic nature of the monetary rule.

\footnotetext{
${ }^{4}$ More specifically, money economizes on credit costs as in Prescott [1987], Dotsey and Ireland [1996] and Lacker and Schreft [1996].

${ }^{5}$ The retail sector can be eliminated, but including it simplifies the presentation of the model.
} 


\subsection{Households}

Households have preferences for consumption and leisure, represented by the timeseparable expected utility function,

$$
\mathbf{E}_{t}\left\{\sum_{j=0}^{\infty} \beta^{j} u\left(c_{t+j}, l_{t+j}\right)\right\}
$$

The period utility function $u(c, l)$ is assumed to be increasing in consumption $c_{t}$ and leisure $l_{t}$, strictly concave and differentiable as needed. Households divide their time allocation - which we normalize to one unit - into leisure, market work $n_{t}$, and transactions time $h_{t}$ so that $n_{t}+l_{t}+h_{t}=1$.

Accumulation of wealth: Households begin each period with a portfolio of claims on the intermediate product firms, holding a previously determined share $\theta_{t}$ of the per capita value of these firms. ${ }^{6}$ This portfolio generates current nominal dividends of $\theta_{t} Z_{t}$ and has nominal market value $\theta_{t} V_{t}$, where $V_{t}$ is measured on a pre-dividend basis for reasons that will be discussed further below. ${ }^{7}$ They also begin each period with a stock of nominal bonds left over from last period which have matured and have market value $B_{t}$. Finally, they begin each period with nominal debt arising from consumption purchases last period, in the amount $D_{t}$. So, their nominal wealth is $\theta_{t} V_{t}+B_{t}-D_{t}-T_{t}$, where $T_{t}$ is the amount of a lump sum tax paid to the government. With this nominal wealth and current nominal wage income $W_{t} n_{t}$, they may purchase money $M_{t}$, buy current period bonds in amount $B_{t+1}$, or buy more claims on the intermediate product firms, each unit of which costs them $\left(V_{t}-Z_{t}\right)$. Thus, they face the constraint

$$
M_{t}+\frac{1}{1+R_{t}} B_{t+1}+\theta_{t+1}\left(V_{t}-Z_{t}\right) \geq \theta_{t} V_{t}+B_{t}-D_{t}-T_{t}+W_{t} n_{t} .
$$

We convert this nominal budget constraint into a real one, using a numeraire $P_{t}$. At present this is simply an abstract measure of nominal purchasing power but we are more specific later about its economic interpretation. Denoting the rate of inflation between period $t-1$ and period $t$ as $\pi_{t}=\frac{P_{t}}{P_{t-1}}-1$, the real flow budget constraint is

$$
m_{t}+\frac{1}{1+R_{t}} b_{t+1}+\theta_{t+1}\left(v_{t}-z_{t}\right) \leq \theta_{t} v_{t}+\frac{b_{t}}{1+\pi_{t}}-\frac{d_{t}}{1+\pi_{t}}-\tau_{t}+w_{t} n_{t},
$$

\footnotetext{
${ }^{6}$ Since this is a representative agent model, there are many equivalent ways of setting up the financial markets in which households can trade. One possibility would be to specify that households can trade Arrow-Debreu securities which pay off a real unit in a single state of the world. If the probability-normalized real price of such a security on future state $\sigma^{\prime}$ is $\rho\left(\sigma, \sigma^{\prime}\right)$ in state $\sigma$, then a household would value the cash flows of the $i$ th firm according to the recursion $v(i, \sigma)=$ $z(i, \sigma)+E\left\{\rho\left(\sigma, \sigma^{\prime}\right) v\left(i, \sigma^{\prime}\right)\right\}$. It would therefore be possible, as Michael Woodford has stressed to us, to derive rather than impose the firm valuation equations that we use in this paper.

${ }^{7} Z_{t}$ and $V_{t}$ are aggregates of the dividends and values of individual firms in a sense that we will also make more precise below.
} 
with lower case letters representing real quantities when this does not produce notational confusion (real lump sum taxes are $\left.\tau_{t}=\frac{T_{t}}{P_{t}}\right){ }^{8}$

Money and transactions: Although households have been described as purchasing a single aggregate consumption good, we now reinterpret this as involving many individual products - technically, a continuum of products on the unit interval - as in many studies following Lucas [1980]. Each of these products is purchased from a separate retail outlet at a price $\bar{P}_{t}$. Each customer buys a fraction $\xi_{t}$ of goods with credit and the remainder with cash. Hence, the households' demand for nominal money satisfies $M_{t}=\left(1-\xi_{t}\right) \bar{P}_{t} c_{t}$. Nominal debt is correspondingly $D_{t+1}=\xi_{t} \bar{P}_{t} c_{t}$, which must be paid next period. Following our convention of using lower case letters to define real quantities, define $\bar{p}_{t} \equiv \frac{\bar{P}_{t}}{P_{t}}$. The real money demand of the household takes the form $m_{t}=\left(1-\xi_{t}\right) \bar{p}_{t} c_{t}$ and similarly $d_{t+1}=\xi_{t} \bar{p}_{t} c_{t}$.

We think of each final consumption good purchase having a random fixed time cost, which must be borne if credit is used. This cost is known after the customer has decided to purchase a specific amount of the product, but before the customer has decided whether to use money or credit to finance the purchase. Let $F(\cdot)$ be the cumulative distribution function for time costs. If credit is used for a particular good, then there are time costs $\nu$ and the largest time cost is given by $\bar{\nu}_{t}=F^{-1}\left(\xi_{t}\right)$. Thus, total time costs are $h_{t}=\int_{0}^{F^{-1}\left(\xi_{t}\right)} \nu d F(\nu)$. The household uses credit when its time cost is below the critical level given by $F^{-1}\left(\xi_{t}\right)$ and uses money when the cost is higher.

\subsubsection{Maximization Problem}

Although the household's individual state vector can be written as its holdings of each asset $(\theta, b, d)$, it is convenient here - as in many other models - to aggregate these assets into a measure of wealth $\varpi=v \theta+\frac{b-d}{1+\pi}-\tau$. We let $U$ be the value function, the indirect lifetime utility function of a household. The recursive maximization problem is then

\footnotetext{
${ }^{8}$ For example $m_{t}=\frac{M_{t}}{P_{t}}$ and $v_{t}, z_{t}$ and $w_{t}$ are similarly defined. The two exceptions are the predetermined variables $B_{t}$ and $D_{t}$, where $b_{t}=\frac{B_{t}}{P_{t-1}}$ and $d_{t}=\frac{D_{t}}{P_{t-1}}$.
} 


$$
\begin{gathered}
U(\varpi ; \sigma)=\max _{\xi, c, l, n, m, \theta^{\prime}, b^{\prime}, d^{\prime}}\left\{u(c, l)+\beta E U\left(\varpi^{\prime} ; \sigma^{\prime}\right) \mid \sigma\right\} \\
\text { subject to } \\
m+\frac{1}{1+R} b^{\prime}+\theta^{\prime}(v-z) \leq \varpi+w n \\
n=1-l-h \\
h=\int_{0}^{F^{-1}(\xi)} \nu d F(\nu) \\
m=(1-\xi) \bar{p} c \\
d^{\prime}=\xi \bar{p} c
\end{gathered}
$$

The right-hand side of $(3)$ is financial wealth plus labor income $(\varpi+w n)$; the lefthand side is purchases of money, discount bonds, and shares (the net cost of stock is its ex-dividend price). The household is assumed to view $w, v, R, z, \bar{p}, \pi$ and $\tau=T / P$ as functions of the state vector, $\sigma$. The conditional expectation $\left.\beta E U\left(\varpi^{\prime} ; \varsigma^{\prime}, s^{\prime}, \phi^{\prime}\right) \mid \sigma\right\}$ is equal to $\left.\int U\left(\varpi^{\prime} ; \varsigma^{\prime}, s^{\prime}, \phi^{\prime}\right) \Upsilon\left(\varsigma, d \varsigma^{\prime}\right)\right\}$, taking as given the laws of motion $s^{\prime}=\Gamma(\sigma)$ and $\phi^{\prime}=\Phi(\sigma)$ discussed above and the definition $\varpi^{\prime}=v^{\prime} \theta^{\prime}+\frac{b^{\prime}-d^{\prime}}{1+\pi^{\prime}}-\tau^{\prime}$. We will return to the discussion of the determinants and consequences of inflation later.

\subsubsection{Efficiency conditions}

We consolidate the household's constraints (3) - (7) into a single constraint, by eliminating hours worked, as is conventional. We also substitute out for money, using $m=(1-\xi) \bar{p} c$, and future debt, using $d^{\prime}=\xi \bar{p} c$ to simplify this constraint further. Let $\lambda$, which has the economic interpretation as the shadow value of wealth, represent the multiplier for this combined constraint. Then, we use the envelope theorem to derive $D_{1} U(\varpi, ; \sigma)=\lambda .^{9}$ We can then state the household's efficiency conditions as

$$
\begin{aligned}
c & : \quad D_{1} u(c, l)=\lambda(1-\xi) \bar{p}+\beta E\left[\lambda^{\prime} \frac{\bar{p}}{1+\pi^{\prime}} \xi\right] \mid \sigma \\
\xi & : \quad \lambda \bar{p} c=\lambda w F^{-1}(\xi)+\beta E\left[\lambda^{\prime} \frac{\bar{p}}{1+\pi^{\prime}} c\right] \mid \sigma \\
l & : \quad D_{2} u(c, l)=w \lambda \\
b^{\prime} & : \quad \frac{1}{1+R} \lambda=\beta E\left[\lambda^{\prime} \frac{1}{1+\pi^{\prime}}\right] \mid \sigma \\
\theta^{\prime} & : \quad(v-z) \lambda=\beta E\left[\lambda^{\prime} v^{\prime}\right] \mid \sigma
\end{aligned}
$$

\footnotetext{
${ }^{9}$ We use "envelope theorem" as short-hand for analyses following Benveniste and Scheinkman [1979], which supply value function derivatives under conditions that ensure differentiability.
} 
as well as (3)-(7). Condition (8) states that the marginal utility of consumption must be equated to the full cost of consuming, which is a weighted average of the costs of purchasing goods with currency and credit. Condition (9) equates the marginal benefit of raising $\xi$ to its net marginal cost, the latter being the sum of the current time cost and the future repayment cost. Condition (10) is the conventional requirement that the marginal utility of leisure is equated to the real wage rate times the shadow value of wealth. The last two conditions specify that holdings of stocks and bonds are efficient.

\section{$2.2 \quad$ Retailers}

Retailers create units of the final good according to a constant elasticity of substitution aggregator of a continuum of intermediate products, indexed on the unit interval, $i \in[0,1] .{ }^{10}$ Retailers create $q$ units of final consumption according to

$$
q=\left[\int q(i)^{\frac{\varepsilon-1}{\varepsilon}} d i\right]^{\frac{\varepsilon}{\varepsilon-1}}
$$

where $\varepsilon$ is a parameter. In our economy, however, there will be groups of intermediate goods-producing firms which will all charge the same price for their good within a period and they can be aggregated easily. Let the $j$-th group have fraction $\omega_{j}$ and charge a nominal price $P_{j}$. Then the retailer allocates its demands for intermediates across the $J$ categories, solving the following problem:

$$
\begin{gathered}
\min _{q_{j}}(1+R) \sum_{j=0}^{J-1} \omega_{j} p_{j} q_{j} \\
\text { subject to } \\
\bar{q}=\left(\sum_{j=0}^{J-1} \omega_{j} q_{j}^{\frac{\varepsilon-1}{\varepsilon}}\right)^{\frac{\varepsilon}{\varepsilon-1}},
\end{gathered}
$$

where $p_{j}=\frac{P_{j}}{P}$ is the relative price of the $j$-th set of intermediate inputs. Retailers view $R$ and $\left\{p_{j}\right\}_{j=0}^{J-1}$ as functions of $\sigma$. The nominal interest factor $(1+R)$ affects the retailer's expenditures because, as is further explained below, the retailer must borrow to finance current production. This cost minimization problem leads to intermediate input demands of a constant elasticity form

$$
q_{j}=\left(p_{j}^{-\varepsilon}\right) \bar{q}
$$

where $\bar{q}$ is the retailer's supply of the composite good. Cost minimization also implies a nominal unit cost of production - an intermediate goods price level of sorts - given

\footnotetext{
${ }^{10}$ Note that this continuum of intermediate goods firms is distinct from the continuum of retail outlets at which consumers purchase final goods.
} 
by

$$
P=\left[\sum_{j=0}^{J-1} \omega_{j} P_{j}^{(1-\varepsilon)}\right]^{\frac{1}{1-\varepsilon}} .
$$

This is the price index which we use as numeraire in the analysis above. As the retail sector is competitive and all goods are produced according to the same technology, it follows that the final goods price must satisfy $\bar{P}=(1+R(\sigma)) P$ and that the relative price of consumption goods is given by

$$
\bar{p}(\sigma)=1+R(\sigma) .
$$

Since they have no market power or specialized factors, retailers earn no profits. Hence, their market value is zero and does not enter in the household budget constraint. At the same time, they are borrowers, making their expenditures at $t$ and receiving their revenues at $\mathrm{t}+1$. That is: for each unit of sales, the retail firm receives revenues in money or credit. Each of these are cash flows which are effectively in date $\mathrm{t}+1$ dollars. If the firm receives money, then it must hold it "overnight." If the firm takes credit, then it is paid only at date $t+1$ with no explicit interest charges, as is the practice with credit cards in many countries.

\subsection{Intermediate goods producers}

The producers of intermediate products are assumed to be monopolistic competitors and face irregularly timed opportunities for price adjustment. For this purpose, we use a general stochastic adjustment model due to Levin [1991], as recently exposited in the Dotsey, King and Wolman [1999] analysis of state dependent pricing. In this setup, a firm which has held its price fixed for $j$ periods will be permitted to adjust with probability $\alpha_{j}$. With a continuum of firms, the fractions $\omega_{j}$ are determined by the recursions $\omega_{j}=\left(1-\alpha_{j}\right) \omega_{j-1}$ for $j=1,2, \ldots J-1$ and the condition that $\omega_{0}=1-\sum_{j=1}^{J-1} \omega_{j}$.

Each intermediate product $i$ on the unit interval is produced according to the production function

$$
y(i)=\operatorname{an}(i)
$$

with labor being paid a nominal wage rate of $W$ and being flexibly reallocated across sectors. Nominal marginal cost for all firms is accordingly $W / a$. Let $p(i) \equiv \frac{P(i)}{P}$ be the $i$-th intermediate goods producer's relative price and $w=\frac{W}{P}$, the real wage, so that real marginal cost is $\psi=w / a$.

Intermediate goods firms face a demand given by

$$
y(i)=p(i)^{-\varepsilon} q(\sigma)
$$

with the aggregate demand measure being $q(\sigma)=c(\sigma)+g(\varsigma)$, i.e., the sum of household and government demand. 


\subsubsection{Maximization Problem}

Intermediate goods firms maximize the present discounted value of their real monopoly profits given the demand structure and the stochastic structure of price adjustment. Using (19) and (20), current profits may be expressed as

$$
z(p(i) ; \sigma)=p(i) y(i)-w(\sigma) n(i)=p(i)^{-\varepsilon} q(\sigma)\left[p(i)-\frac{w(\sigma)}{a(\varsigma)}\right] .
$$

All firms that are adjusting at date $t$ will choose the same nominal price, which we call $P_{0}$, which implies a relative price $p_{0}=\frac{P_{0}}{P}$. The mechanical dynamics of relative prices are simple to determine. Given that a nominal price is set at a level $P_{j}$, then the current relative price is $p_{j}=P_{j} / P$. If no adjustment occurs in the next period, then the future relative price satisfies

$$
p_{j+1}^{\prime}=\frac{p_{j}}{1+\pi^{\prime}} .
$$

A price-setting intermediate goods producer solves the following maximization problem:

$$
v^{0}(\sigma)=\max _{p_{0}}\left[z\left(p_{0} ; \sigma\right)+E\left\{\beta \frac{\lambda\left(\sigma^{\prime}\right)}{\lambda(\sigma)}\left[\alpha_{1} v^{0}\left(\sigma^{\prime}\right)+\left(1-\alpha_{1}\right) v^{1}\left(p_{1}^{\prime}, \sigma^{\prime}\right)\right]\right\} \mid \sigma\right],
$$

with the maximization taking place subject to $p_{1}^{\prime}=\frac{P_{1}^{\prime}}{P^{\prime}}=\frac{P_{0}}{P} \frac{P}{P^{\prime}}=p_{0} /\left(1+\pi^{\prime}\right)$. A few comments about the form of this equation are in order. First, the discount factor used by firms equals households' shadow value of wealth in equilibrium, so we impose that requirement here. Second, as is implicit in our profit function, the firm is constrained by its production function and by its demand curve, which depends on aggregate consumption and government demand. Third, the firm knows that at date $t+1$, with probability $\alpha_{1}$ it will adjust its price and the current pricing decision will be irrelevant to its market value $\left(v^{0}\right)$. With probability $1-\alpha_{1}$ it will not adjust its price and the current price will be maintained, resulting in a market value $v^{1}$. Our notation is that the superscript $j$ in $v^{j}$ indicates the value of a firm which is maintaining its price fixed at the level set at date $t-j$, i.e., $P_{j, t}=P_{0, t-j}$. Thus, we have for $j=1, \ldots, J-2$,

$$
v^{j}\left(p_{j}, \sigma\right)=z\left(p_{j} ; \sigma\right)+E\left\{\beta \frac{\lambda\left(\sigma^{\prime}\right)}{\lambda(\sigma)}\left[\alpha_{j+1} v^{0}\left(\sigma^{\prime}\right)+\left(1-\alpha_{j+1}\right) v^{j+1}\left(p_{j+1}^{\prime}, \sigma^{\prime}\right)\right]\right\} \mid \sigma,
$$

with $p_{j+1}^{\prime}=\frac{p_{j}}{1+\pi^{\prime}}$. Finally, in the last period of price fixity, all firms know that they will adjust for certain so that

$$
v^{J-1}\left(p_{J-1}, \sigma\right)=z\left(p_{J-1} ; \sigma\right)+E\left\{\beta \frac{\lambda\left(\sigma^{\prime}\right)}{\lambda(\sigma)}\left[v^{0}\left(\sigma^{\prime}\right)\right]\right\} \mid \sigma .
$$

These expressions imply that the aggregate portfolio value and dividends, denoted $v_{t}$ and $z_{t}$ in the household's problem, are determined as $v_{t}=\sum_{j=0}^{J-1} \omega_{j} v^{j}\left(p_{j, t}, \sigma\right)$ and 
$z_{t}=\sum_{j=0}^{J-1} \omega_{j} z\left(p_{j, t}, \sigma\right)$. Our decision to earlier write the stock market portfolio in predividend value terms was based on having a ready match with the natural dynamic program for the firm's pricing decisions.

\subsubsection{Efficiency conditions}

In order to satisfy $(23)$, the optimal pricing decision requires $p_{0}$ to solve

$$
0=D_{1} z\left(p_{0} ; \sigma\right)+\beta E\left\{\frac{\lambda^{\prime}}{\lambda}\left(1-\alpha_{1}\right) D_{1} v^{1}\left(p_{1}^{\prime} ; \sigma^{\prime}\right) \frac{1}{1+\pi^{\prime}}\right\} \mid \sigma
$$

From (21), marginal profits are given by

$$
D_{1} z\left(p_{j} ; \sigma\right)=q(\sigma)\left[(1-\varepsilon) p_{j}^{-\varepsilon}+\varepsilon \frac{w(\sigma)}{a(\sigma)} p_{j}^{-\varepsilon-1}\right] .
$$

The optimal pricing condition (26) states that, at the optimum, a small change in price has no effect on the present discounted value. The presence of future inflation reflects the fact that $p_{1}^{\prime}=p_{0} /\left(1+\pi^{\prime}\right)$, so that when the firm perturbs its relative price by $d p_{0}$, it knows that it is also changing its one period ahead relative price by $\left[1 /\left(1+\pi^{\prime}\right)\right] d p_{0} \cdot{ }^{11}$ Equations (24) imply

$$
D_{1} v^{j}\left(p_{j} ; \sigma\right)=D_{1} z\left(p_{j} ; \sigma\right)+\beta E\left\{\frac{\lambda^{\prime}}{\lambda}\left(1-\alpha_{j+1}\right) D_{1} v^{j+1}\left(p_{j+1}^{\prime} ; \sigma^{\prime}\right) \frac{1}{1+\pi^{\prime}}\right\} \mid \sigma
$$

for $j=1, \ldots, J-2$, while (25) implies

$$
D_{1} v^{J-1}\left(p_{J-1} ; \sigma\right)=D_{1} z\left(p_{J-1} ; \sigma\right)
$$

\subsection{Defining the state vector $\mathrm{s}$}

We next consider the price component of the aggregate state vector. The natural state is the vector of previously determined nominal prices, $\left[P_{1, t} P_{2, t} \ldots P_{J-1, t}\right]$. Given these predetermined nominal prices and the nominal price $P_{0, t}$ set by currently adjusting firms, the price level $P_{t}$ is $\left[\sum_{j=0}^{J-1} \omega_{j} P_{j, t}^{(1-\varepsilon)}\right]^{\frac{1}{1-\varepsilon}}$. However, our analysis concerns (i) households and firms that are concerned about real objectives as described above; and (ii) a monetary authority who seeks to maximize a real objective as described below. Accordingly, neither is concerned about the absolute level of prices in the initial period

\footnotetext{
${ }^{11}$ An individual firm chooses $p_{0}(i)$ taking as given the actions of all other firms - including other adjusting firms - as these affect the price level, aggregate demand and so forth. Specifically, firm $i$ views the actions of other adjusting firms as $p_{0}(\sigma)$, with a law of motion for $\sigma$ described earlier. In an equilibrium, there is a fixed point in that the decision rule of the individual firm $p(i, \sigma)$ is equal to the function $p_{0}(\sigma)$.
} 
of our model (i.e., the time at which the monetary policy rule is implemented). For this reason, we opt to use an alternative real state vector that captures the influence of predetermined nominal prices, but is compatible with any initial scale of nominal prices.

There are a variety of choices that one might make in defining this real state vector, with the decision based on how completely one seeks to cast the optimal policy problem in terms of real quantities and computational considerations. ${ }^{12,13}$ In the current analysis, we instead use the simplest and most direct state vector: a vector of lagged relative prices.

The relative prices that will prevail in the economy at date $t$ are $p_{0, t}, p_{1, t}, \ldots, p_{J-1, t}$. Since nominal prices are sticky $\left(P_{j, t}=P_{j-1, t-1}\right)$, it follows that

$$
p_{j, t}=\frac{P_{j, t}}{P_{t}}=\frac{P_{j-1, t-1}}{P_{t-1}} \frac{P_{t-1}}{P_{t}}=\frac{p_{j-1, t-1}}{1+\pi_{t}}
$$

for $j=1,2, \ldots J-1$. Accordingly, given current inflation, we can account for the relative prices of sticky prices goods so long as we know $p_{j, t-1}$ for $j=0,1,2, \ldots J-2$. These $J-1$ lagged relative prices thus are chosen to be our real state vector, so that $s_{t-1}=\left[p_{0, t-1} \ldots p_{J-2, t-1}\right]$.

\subsection{Monetary policy}

Monetary policy determines the nominal quantity of money. However, just as we normalized lagged nominal prices by the past price level, it is convenient to similarly deflate the money stock. With this normalization, we denote the policy rule by $\mathfrak{M}\left(\sigma_{t}\right)$, and the nominal money supply is given by

$$
M_{t}=\mathfrak{M}\left(\sigma_{t}\right) \cdot P_{t-1} \text {. }
$$

Real balances are given by $m_{t}=\mathfrak{M}\left(\sigma_{t}\right) \cdot \frac{P_{t-1}}{P_{t}}=\frac{\mathfrak{M}\left(\sigma_{t}\right)}{1+\pi_{t}} \cdot{ }^{14}$

\footnotetext{
${ }^{12}$ For example, King and Wolman [1999] use a state vector that is a vector of lagged real demand ratios, $c_{j, t-1} / c_{j+1, t-1}$ for $j=0,1, \ldots J-3$, in order to cast the monetary authority's problem as solely involving real quantities.

${ }^{13}$ Computational considerations might lead one to (i) make the state vector $s_{t-1}=\left(P_{j, t} / \widehat{P}_{t}\right)_{j=1}^{J-2}$ where $\widehat{P}_{t}=\left[\frac{1}{1-\omega_{0}} \sum_{h=1}^{J-1} \omega_{j} P_{j, t}^{(1-\varepsilon)}\right]^{\frac{1}{1-\varepsilon}}$ is an index of the predetermined part of the price level; and (ii) use related manipulations to eliminate the inflation rate as a current decision variable for the monetary authority. The computational advantage derives from the fact that there are then only $J-2$ elements of the state vector, whereas there are $J-1$ elements with the approach presented in the text.

${ }^{14}$ It is clear from (31) that if the policy rule involves no response to the state, then this generally does not make the nominal money supply constant, because a constant $\mathfrak{M}()$ implies $M_{t}=\mathfrak{M} \cdot P_{t-1}$, meaning that the path of the money supply is proportional to the past price level. If the monetary authority makes the nominal money supply constant, it must make the past price level part of the state vector, because a constant money supply $M$ implies $\mathfrak{M}\left(\sigma_{t}\right)=M / P_{t-1}$.
} 
With the general function $\mathfrak{M}\left(\sigma_{t}\right)$ we are not taking a stand on the targets or instruments of monetary policy. This notation makes clear, however, that the monetary authority's optimal decisions will depend on the same set of state variables as the decisions of the private sector.

\subsection{Recursive equilibrium}

We now define a recursive equilibrium in a manner that highlights the key elements of the above analysis. ${ }^{15}$

Definition. For a given monetary policy function $\mathfrak{M}(\sigma)$, a Recursive Equilibrium is a set of relative price functions $\lambda(\sigma), w(\sigma),\left\{p_{j}(\sigma)\right\}_{j=0}^{J-1}$, and $\bar{p}(\sigma)$; an interest rate function $R(\sigma)$; an inflation function $\pi(\sigma)$; aggregate production, $q(\sigma)$; dividends, $z(\sigma)$; intermediate goods producers' profits $\left\{z_{j}(\sigma)\right\}_{j=0}^{J-1}$; value functions $U(\cdot)$ and $\left\{v^{j}(\cdot)\right\}_{j=0}^{J-1}$; household decision rules $\left\{\xi(\sigma), c(\sigma), l(\sigma), n(\sigma), m(\sigma), \theta^{\prime}(\sigma), b^{\prime}(\sigma)\right.$,

$\left.d^{\prime}(\sigma)\right\}$; intermediate goods producers' relative quantities, $\left\{q_{j}(\sigma)\right\}_{j=0}^{J-1}$; intermediate goods producers' relative prices, $\left\{p_{j}(\sigma)\right\}_{j=0}^{J-1}$ and a law of motion for the aggregate state $\sigma=(\varsigma, s, \phi), \varsigma^{\prime} \sim \Upsilon(\varsigma, \cdot), s^{\prime}=\Gamma(\sigma)$ and $\phi^{\prime}=\Phi(\sigma)$ such that: (i) households solve (2) - (7), (ii) retailers solve (14) - (15), (iii) price-setting intermediate goods producers solve (22) - (25), and (iv) markets clear.

While this definition describes the elements of the discussion above that are important to equilibrium, it is useful to note that a positive analysis of this equilibrium can be carried out without determining the value functions $U(\cdot)$ and $\left\{v^{j}(\cdot)\right\}_{j=0}^{J-1}$, but by simply relying on the first-order conditions. We exploit this feature in our analysis of optimal policy.

\section{Optimal policy approach}

Our analysis of optimal policy is in the tradition of Ramsey [1927] and draws heavily on the modern literature on optimal policy in dynamic economies which follows from Lucas and Stokey [1983]. In this paper, as in King and Wolman [1999], we adapt this approach to an economy which has real and nominal frictions. Here those frictions are monopolistic competition, price stickiness and the costly conversion of wealth into goods, with the cost affected by money holding. The outline of our multi-stage approach is as follows. First, we have already determined the efficiency conditions of households and firms that restrict dynamic equilibria, as well as the various bud-

\footnotetext{
${ }^{15}$ The household's real budget constraint (3) is not included in the equations that restrict equilibrium, as in many other models, since it is implied by market clearing and the government budget constraint. In equilibrium, $\theta=1, b-d=0$, and $\tau=g$ so that $\varpi=v-g$. Thus, current inflation, $\pi_{t}$, does not enter into the household's decisions. Howevever, it does enter into the dynamics of relative prices.
} 
get and resource constraints. Second, we manipulate these equations to determine a smaller subset of restrictions that govern key variables, in particular eliminating $\mathfrak{M}\left(\sigma_{t}\right)$ so that it is clear that we are not taking a stand on the monetary instrument. Third, we maximize expected utility subject to these constraints. Fourth, we find the absolute prices and monetary policy actions which lead these outcomes to be the result of dynamic equilibrium. ${ }^{16}$

\subsection{Organizing the restrictions on dynamic equilibria}

We begin by organizing the equations of section 2 so that they are a set of constraints on the policy maker. To aid in this process and in the statement of the optimal monetary policy problem as an infinite horizon dynamic optimization problem in the next subsection, it becomes useful to reintroduce time subscripts throughout this section.

\subsubsection{Restrictions implied by technology and relative demand}

The first constraint is associated with production. Since $n_{t}=\sum_{j=0}^{J-1} \omega_{j} n_{j, t},(19)$ gives

$$
a_{t} n_{t}=\left(\sum_{j=0}^{J-1} \omega_{j} p_{j, t}^{-\varepsilon}\right)\left(c_{t}+g_{t}\right) .
$$

The second constraint is associated with the aggregation of intermediate goods in (13),

$$
1=\left[\sum_{j=0}^{J-1} \omega_{j} p_{j, t}^{1-\varepsilon}\right]^{\frac{1}{1-\varepsilon}} .
$$

\subsubsection{Restrictions implied by state dynamics}

With staggered pricing, the dynamics of the states is just given by (30). Defining the state vector $s_{t}=\left[\begin{array}{lll}p_{0 t} & \ldots & p_{J-2, t}\end{array}\right]$, we can write its dynamic equation in the form discussed above, $s_{t}=\Gamma\left(s_{t-1}, p_{0 t}, \pi_{t}\right)$ where $\Gamma$ takes the form

$$
\left[\begin{array}{c}
s_{1 t} \\
s_{2, t} \\
\cdot \\
\cdot \\
s_{J-1, t}
\end{array}\right]=\left[\begin{array}{cc}
\mathbf{0} & 0 \\
\frac{1}{1+\pi_{t}} \cdot \mathbf{I} & \mathbf{0}^{\prime}
\end{array}\right]\left[\begin{array}{c}
s_{1, t-1} \\
s_{2, t-1} \\
\cdot \\
\cdot \\
s_{J-1, t-1}
\end{array}\right]+\left[\begin{array}{c}
1 \\
0 \\
\cdot \\
\cdot \\
0
\end{array}\right] p_{0, t}
$$

where $\mathbf{I}$ is an identity matrix with $J-2$ rows and columns and $\mathbf{0}$ is a row vector with $J-2$ elements

\footnotetext{
${ }^{16}$ We rule out policies that involve randomization, in contrast to Bassetto [1999] and Dupor [2002].
} 


\subsubsection{Restrictions implied by household behavior}

The household's decision rules are implicitly restricted by the equations (3) - (7) and (8) - (12). A planner must respect all of these conditions, but it is convenient for us to use some of them to reduce the number of choice variables, while retaining others. In particular, combining (8), (11) and (18), we find that the household requires that the marginal utility of consumption is equated to a measure of the full price of consumption, which depends on $\lambda_{t}$ as is conventional, but also on $R_{t}$ and $\xi_{t}$ because money or credit must be used to obtain consumption:

$$
D_{1} u\left(c_{t}, l_{t}\right)=\lambda_{t}\left[1+R_{t}\left(1-\xi_{t}\right)\right] .
$$

Combining (9), (10), (11) and (18), the efficient choice between money and credit as a means of payment is restricted by

$$
R_{t} c_{t}=w_{t} F^{-1}\left(\xi_{t}\right)=\frac{D_{2} u\left(c_{t}, l_{t}\right)}{\lambda_{t}} F^{-1}\left(\xi_{t}\right)
$$

which indicates how credit use is related to market prices and quantities. Since $\xi=1-\frac{M}{\bar{P} c}$, this restriction implicitly defines the demand for money, $\frac{M}{\bar{P} c}=1-F\left(\frac{R c}{w}\right)$, as a function of a small number of variables, which is the basis for our empirical work below.

The nominal interest rate enters into each of these equations but, since it is an intertemporal price, it also enters in the bond efficiency condition (11),

$$
\lambda_{t} \frac{1}{1+R_{t}}=\beta E_{t}\left[\lambda_{t+1} \frac{1}{1+\pi_{t+1}}\right]
$$

which is a forward-looking constraint, reflecting the intertemporal nature of (11).

Combining equations (4) and (5) to eliminate transactions time, we can write

$$
n_{t}=1-l_{t}-\int_{0}^{F^{-1}\left(\xi_{t}\right)} \nu d F(\nu)=n\left(l_{t}, \xi_{t}\right)
$$

so that only $l_{t}$ and $\xi_{t}$ are choices for the optimal policy problem.

We do not ignore the other household conditions, but rather use them to construct variables which do not enter directly in the optimal policy problem, but are relevant for the decentralization, such as real money demand as $m_{t}=\left(1-\xi_{t}\right) \bar{p}_{t} c_{t}=m\left(c_{t}, l_{t}, \xi_{t}\right)$ and real transactions debt as $d_{t+1}=\xi_{t} \bar{p}_{t} c_{t}=d\left(c_{t}, l_{t}, \xi_{t}\right)$.

\subsubsection{Restrictions implied by firm behavior}

Price-setting behavior of intermediate good producers is captured by the marginal value functions (26) - (29) which we rewrite by multiplying by $\lambda_{t} \omega_{j} p_{j, t}$. This yields 


$$
\begin{gathered}
0=\omega_{0} x\left(p_{0, t}, c_{t}, l_{t}, \lambda_{t}, g_{t}, a_{t}\right)+\beta E_{t}\left[\chi_{1, t+1}\right] \\
\chi_{j, t}=\omega_{j} x\left(p_{j, t}, c_{t}, l_{t}, \lambda_{t}, g_{t}, a_{t}\right)+\beta E_{t}\left[\chi_{j+1, t+1}\right] \\
\chi_{J-1, t}=\omega_{J-1} x\left(p_{J-1, t}, c_{t}, l_{t}, \lambda_{t}, g_{t}, a_{t}\right),
\end{gathered}
$$

where (39) holds for $j=1,2, \ldots J-2$. In these expressions, the $x$ function is defined as

$$
x\left(p_{j, t}, c_{t}, l_{t}, \lambda_{t}, g_{t}, a_{t}\right)=\left(c_{t}+g_{t}\right)\left(\lambda_{t}(1-\varepsilon) p_{j, t}^{1-\varepsilon}+\varepsilon \frac{D_{2} u\left(c_{t}, l_{t}\right)}{a_{t}} p_{j, t}^{-\varepsilon}\right),
$$

and the $\chi_{j, t}$ are defined as

$$
\chi_{j, t}=\left[\omega_{j} \lambda_{t} p_{j, t} D_{1} v^{j}\left(p_{j, t}\right)\right] .
$$

Note that the function $x\left(p_{j, t}, c_{t}, l_{t}, \lambda_{t}, g_{t}, a_{t}\right)$ is simply shorthand while, by contrast, the variables $\chi_{j, t}$ actually replace the expression $\omega_{j} \lambda_{t} p_{j, t} D_{1} v^{j}\left(p_{j, t}\right)$.

\subsection{The optimal policy problem}

The monetary policy authority maximizes (1) subject to the constraints just derived, which include a number of constraints that introduce expectations of future variables into the time $t$ constraint set. One way to proceed is to define a Lagrangian for the dynamic optimization problem, with the result being displayed in Table 1. In this Lagrangian, $\mathbf{d}_{t}$ is a vector of decisions that includes real quantities, some other elements, inflation $\left(\pi_{t}\right)$ and the nominal interest rate $\left(R_{t}\right)$. Similarly, $\boldsymbol{\Lambda}_{t}$ is a vector of Lagrange multipliers chosen at $t$. This problem also takes the initial exogenous

$\left(\varsigma_{0}\right)$ and endogenous states $s_{-1}=\left(s_{j,-1}\right)_{j=1}^{J-2}$ as given. Finally, it embeds the various definitions above, including $x\left(p_{j, t}, c_{t}, l_{t}, \lambda_{t}, g_{t}, a_{t}\right)$ etc.

In Table 1, there are two types of constraints to which we attach multipliers. The first three lines correspond to the forward-looking constraints: (36), the Fisher equation, and (38) - (40), which are the implementation constraints arising from dynamic monopoly pricing. We stress these constraints by listing them first in Table 1 and in other tables below. The remainder are conventional constraints which either describe point-in-time restrictions on the planner's choices or the evolution of the real state variables that the planner controls.

One can then find the first order conditions to this optimization problem. Because the problem is dynamic and has fairly large dimension at each date, there are many such conditions. Further, as is well-known since the work of Kydland and Prescott [1977], such optimal policy problems under commitment with forward-looking constraints are inherently nonstationary. As an example of this aspect of the policy problem, consider the first order condition with respect to $\chi_{j, t}$ for some $j$ satisfying 
$0<j<J-1$ which would arise if uncertainty is momentarily assumed absent. At date 0 , this condition takes the form

$$
0=-\phi_{j, 0}
$$

but for later periods, it takes the form

$$
0=\left\{\phi_{j-1, t-1}-\phi_{j, t}\right\}
$$

Notice that the difference between these two expressions is the presence of a lagged multiplier, so that they would be identical if $\phi_{j-1,-1}$ were added to the right-hand side of the former.

\subsubsection{A stationary reformulation of the optimal policy problem}

We now introduce lagged multipliers corresponding to the forward-looking constraints in the initial period. In doing so, we generalize the Lagrangian to that displayed in Table 2, effectively making the problem stationary.

The Fisher equation (36): For each date $s, \lambda_{s}$ appears in period $s-1$ via the expression $-E_{s-1} \varphi_{s-1} \frac{1}{1+\pi_{s}} \lambda_{s}$ and then in period $s$ as $\beta E_{s} \varphi_{s} \frac{1}{1+R_{s}} \lambda_{s}$. By contrast, no such first term is attached to $\lambda_{0}$. To make the first order conditions time invariant, we therefore add $-\beta \varphi_{-1} \frac{1}{1+\pi_{0}} \lambda_{0}$, which introduces the lagged multiplier $\varphi_{-1}$ into our problem.

Implementation constraints arising from intermediate goods pricing (38 - 40): There are a number of implications of the constraints involving optimal price-setting by the intermediate goods firms.

First, $\chi_{1, s}$ typically appears in period $s-1$ as $\beta E_{s-1} \phi_{0, s-1} \chi_{1, s}$ and in period $s$ as $E_{s} \phi_{1, s} \chi_{1, s}$. The exception is $\chi_{1,0}$ which does not have the first term. We therefore append the term, $\beta \phi_{0,-1} \chi_{1,0}$ to the optimization problem, which introduces another lagged multiplier, $\phi_{0,-1}$.

Second, for each $j=2, \ldots, J-2, \chi_{j, s}$ enters the problem twice, in $\beta E_{s-1} \phi_{j-1, s-1} \chi_{j, s}$ and in $-E_{s} \phi_{j, s} \chi_{j, s}$. Again, an exception is $\chi_{j, 0}$ which does not have the first term. We add these terms, $\beta \phi_{j-1,-1} \chi_{j, 0}$ for $j=2, \ldots, J-2$. This introduces the lagged multipliers $\phi_{1,-1}, \ldots, \phi_{J-3,-1}$

Finally, $\chi_{J-1, s}$ usually enters the problem twice, in $\beta E_{s-1} \phi_{J-2, s-1} \chi_{J-1, s}$ and in $-E_{s} \phi_{J-1, s} \chi_{J-1, s}$. As above, an exception is $\chi_{J-1,0}$ which does not have the first term. We add the term $\beta \phi_{J-2,-1} \chi_{J-1,0}$ to our problem and, hence, introduce the lagged multiplier $\phi_{J-2,-1}$.

It is important to stress that the problem in Table 2 contains that in Table 1 as a special case: if we set the lagged multipliers $\left[\varphi_{-1},\left(\phi_{j,-1}\right)_{j=0}^{J-2}\right]$ all to 0 , then we have exactly the same problem as before. Accordingly, we can always find the solution to the Table 1 problem from the Table 2 problem. However, the first-order conditions to Problem 2 are a system of time-invariant functions because of the introduction of the lagged multipliers, which is convenient for the analysis of optimal policies. 
Before turning to this topic, note that in Table 2 we define $U^{*}\left(s_{-1}, \phi_{-1}, \varsigma_{0}\right)$ as the value of the Lagrangian evaluated at the optimal decisions, where $\phi_{-1}=$ $\left[\varphi_{-1},\left(\phi_{j,-1}\right)_{j=0}^{J-2}\right]$. This value function for the optimal policy problem has two important properties. First, it depends on the parameters of the problem, which here are $s_{-1}, \phi_{-1}, \varsigma_{0}$. Second, it is the solution to the problem of maximizing the objective (1) subject to the constraints discussed above, so we use the notation $U^{*}$ to denote the planner's value function.

\subsubsection{The fully recursive form of the policy problem}

Working on optimal capital taxation under commitment, Kydland and Prescott [1980] began the analysis of how to solve such dynamic policy problems using recursive methods. They proposed augmenting the traditional state vector with a lagged multiplier as above and then described a dynamic programming approach. Important recent work by Marcet and Marimon [1999] formally develops the general theory necessary for a recursive approach to such problems. In our context, the fully recursive form of the policy problem is displayed in Table 3. There are a number of features to point out. First, the state vector for the policy problem is given by $\varsigma_{t}, s_{t-1}$ and $\phi_{t-1} \equiv\left[\varphi_{t-1},\left(\phi_{j, t-1}\right)_{j=0}^{J-2}\right]$. That is: we have now determined the extra state variables to which the monetary authority was viewed as responding in section 2 above. Second, we can write the optimal policy problem in a recursive form similar to a Bellman equation; Marcet and Marimon [1999] label this recursive form as a saddlepoint functional equation. Third, as $E_{t} U^{*}\left(s_{t}, \phi_{t}, \varphi_{t+1}\right)$ summarizes the future effects of current choices, there is a simplification of the problem in that explicit future constraints are eliminated.

\subsection{FOCs, Steady States, and Linearization}

Given the policy problem as described in Table 2 or 3 , it is straightforward to determine the first order conditions that characterize optimal policy. ${ }^{17}$ These first order conditions may be represented as a system of equations of the form

$$
0=E_{t}\left\{\mathbf{F}\left(\underline{Y}_{t+1}, \underline{Y}_{t}, \underline{X}_{t+1}, \underline{X}_{t}\right)\right\}
$$

where $\underline{Y}_{t}$ is the vector of all endogenous states, multipliers, and decisions and $\underline{X}_{t}$ is a vector of exogenous variables. In our context, $\underline{Y}_{t}=\left[\eta_{t}, \varsigma_{t},, c_{t}, l_{t}, \xi_{t}, \pi_{t},\left(p_{j, t}\right)_{j=1}^{J-1},\left(\chi_{j, t}\right)_{j=0}^{J-1}\right.$, $\left.s_{t-1}, \phi_{t-1}\right]^{\prime}$ and $\underline{X}_{t}=\left[a_{t}, g_{t}\right]^{\prime}$.

Our computational approach involves two steps. First, we calculate a stationary point defined by $\mathbf{F}(\underline{Y}, \underline{Y}, \underline{X}, \underline{X})=0$. Second, we log-linearize the above system and

\footnotetext{
${ }^{17}$ Either the augmented Lagrangian of Table 2 or the recursive approach of Table 3 can be used to analyze the optimal policy problem. These two expressions lead to identical first-order conditions, after envelope-theorem results are derived for the problem in Table 3.
} 
calculate the local dynamic behavior of quantities and prices given a specified law of motion for the exogenous states $\varsigma$, which is also taken to be log-linear.

\section{Four distortions}

Our macroeconomic model has the property that there are four readily identifiable routes by which nominal factors can affect real economic activity.

\subsection{Defining the distortions}

We discuss these four distortions in turn, using general ideas that carry over to a wider class of macroeconomic models.

Relative price distortions: In any model with asynchronous adjustment of nominal prices, there are distortions that arise when the price level is not constant. In our model, the natural measure of these distortions is

$$
\delta_{t}=\frac{a_{t} n_{t}}{\left(c_{t}+g_{t}\right)}=\left[\sum_{j=0}^{J} \omega_{j}\left(P_{j, t} / P_{t}\right)^{-\varepsilon}\right] .
$$

If all relative prices are unity, then $\delta$ takes on a value of one. If relative prices deviate from unity, which is the unconstrained efficient level given the technology, then $\delta_{t}$ measures the extent of lost aggregate output which arises for this reason.

The markup distortion: If all firms have the same marginal cost functions, then we can write $W_{t}=\Psi_{t} a_{t}$. Here $W$ is the nominal wage, $\Psi_{t}$ is nominal marginal cost and $a_{t}$ is the common marginal product of labor. If we divide by the perfect (intermediate good) price index, then this expression can be stated in real terms as

$$
w_{t}=\psi_{t} a_{t}
$$

so that real marginal cost $\psi_{t}$ acts like a sales tax shifter.

Some recent literature has described this second source of distortions in terms of the average markup $\mu_{t} \equiv P_{t} / \Psi_{t}$, which is the reciprocal of real marginal cost $\psi_{t}$, stressing that the monetary authority has temporary control over this markup tax because prices are sticky, enabling it to erode (or enhance) the markups of firms with sticky prices. ${ }^{18}$ According to this convention, which we follow here, a higher value of the markup lowers real marginal cost and works like a tax on productive activity.

Since movements in $\delta_{t}$ and $\mu_{t}$ (or $\psi_{t}$ ) are not necessarily related closely together, it is best to think about these two factors from the standpoint of fiscal policy - which can generate separate shocks to the level of the production function and its marginal products - rather than the standpoint of productivity shocks which traditionally shift both in RBC analysis.

\footnotetext{
${ }^{18}$ See Woodford [1995], King and Wolman [1996] and Goodfriend and King [1997].
} 
Inefficient shopping time: The next distortion is sometimes referred to as "shoe leather costs." But in our model, it is really "shopping time costs," as in McCallum and Goodfriend [1988], since it is in units of time rather than goods. In (37) above, it is $h_{t}=\int_{0}^{F^{-1}\left(\xi_{t}\right)} \nu d F(\nu)$. Variations in $h_{t}$ work like a shock to the economy's time endowment. Continuing the fiscal analogy begun above, this is similar to a conscription (lump sum labor tax).

The wedge of monetary inefficiency: In transactions-based monetary models, there is also an effect of monetary policy on the full cost of consumption, which occurs in (34) above, $D_{1} u\left(c_{t}, l_{t}\right)=\lambda_{t}\left[1+R_{t}\left(1-\xi_{t}\right)\right]$. The wedge of monetary inefficiency in this equation is the product of the nominal interest rate and the extent of monetization of exchange $\left(1-\xi_{t}\right)$. Pursuing our fiscal policy analogy, it is like a consumption tax relative to the non-monetary model.

\subsection{Selectively eliminating one or more distortions}

Since the four distortions all enter into our model, it can be difficult to determine which distortion is giving rise to a particular result. In our analysis below, we selectively eliminate one or more distortions. In doing so, we are imagining that there is a fiscal authority which can offset the distortions in the following ways.

Eliminating variations in relative price distortions. This modification involves resolving the model with $\delta\left(c_{t}+g_{t}\right)=a_{t} n_{t}$ replacing $\delta_{t}\left(c_{t}+g_{t}\right)=a_{t} n_{t}$. Since relative price distortions affect the constraint $\delta_{t}\left(c_{t}+g_{t}\right)=a_{t} n_{t}$ but do not affect the marginal costs of firms or the wages of workers, they can be interpreted as an additive productivity shock-relative to a benchmark level of $\delta$-with an effect of $\left(1 / \delta_{t}-1 / \delta\right) a_{t} n_{t}$. Accordingly, the elimination of relative price distortions can be understood as involving a fiscal authority which decreases its spending by an amount $\widetilde{g}_{t}=\left(\delta^{-1}-\delta_{t}^{-1}\right) a_{t} n_{t}$, where $\delta$ is a benchmark level of distortions with $\delta=1$ corresponding to no distortions. Total government spending would then be $g_{t}-\widetilde{g}_{t}$.

Eliminating variation in the markup distortion. This involves re-solving the model with $w_{t}=\psi a_{t}$ replacing $w_{t}=\psi_{t} a_{t}=\frac{1}{\mu_{t}} a_{t}$. Using the idea that the markup is like a sales tax, we can think of this as involving a fiscal authority which adjusts an explicit sales/subsidy tax on intermediate goods producers so that $\left(1+\tau_{t}^{i}\right) \frac{1}{\mu_{t}}=\left(1+\tau^{i}\right)$, where $\left(1+\tau^{i}\right)=\psi$ is a benchmark level of the net tax on intermediate goods producers from the two sources.

Eliminating variations in inefficient shopping time. Eliminating variations in the resources used by credit involves holding the right hand side of $l_{t}+n_{t}=1-h_{t}$ fixed. A fiscal interpretation of this alteration is that a fiscal authority varies the amount of its lump sum confiscation of time similarly to the changes in lump sum confiscation of goods discussed for relative price distortions.

Eliminating variations in the wedge of monetary inefficiency. This modification involves holding $\left(1+\left(1-\xi_{t}\right) R_{t}\right)$ fixed at a specified level. A fiscal interpretation is that there is a consumption tax rate which is varied so that $\left(1+\left(1-\xi_{t}\right) R_{t}\right)\left(1+\tau_{t}^{c}\right)$ 
is held constant at a specified level.

\subsection{Distortions under "neutral" policy}

One possible choice for the monetary authority of real outcomes is sometimes described as neutral policy, as in Goodfriend and King [1997]. It involves making the path of the price level constant through time, thus minimizing relative price distortions but leaving the markup at $\mu=\frac{\varepsilon}{\varepsilon-1}$ and allowing variations in the two monetary distortions as the real economy fluctuates over time in response to variations in the real conditions $g_{t}$ and $a_{t}$. Under this regime, real activity fluctuates in a manner which is identical to how it would behave if prices were flexible and if the monetary authority stabilized the price level. In its essence, this is the Fisherian proposal for eliminating business fluctuations via price stabilization.

At least after a brief startup period associated with working off an inherited distribution of relative prices, such an outcome is always feasible for the monetary authority in our economy. To the extent that the monetary authority chooses to depart from these neutral outcomes, it is because it is responding to the distortions identified in this section. As one example, a monetary authority might choose a lower average rate of inflation, to reduce time costs, as suggested by Friedman. As another example, a monetary authority might choose to stabilize the fluctuations in real economic activity that would occur under neutral policy, changing the extent to which the markup distortion is present in booms and contractions. Such stabilization policy would be of the general form advocated by Keynes.

\section{Choice of parameters}

Given the limited amount of existing research on optimal monetary policy using the approach of this paper and given the starkness of our model economy, we have chosen the parameters with two objectives in mind. First, we want our economy to be as realistic as possible, so we calibrate certain parameters to match certain features of the U.S. economy as discussed below. Second, we want our economy to be familiar to economists who have worked with related models of business cycles, fiscal policy, money demand, and sticky prices. Our benchmark parametric model is as follows, with the time unit taken to be one quarter of a year.

\subsection{Preferences}

We assume the utility function is logarithmic, $u(c, l)=\ln c+3.3 \ln (l)$, with the weight on leisure parameter being set so that agents work approximately 0.20 of available time. We assume also that the discount factor is such that the annual interest rate would be slightly less than three percent $(\beta=0.9928)$. This choice of the discount factor is governed by data on one year T-bill rates and the GDP deflator. 


\subsection{Monopoly power}

We assume that the demand elasticity, $\varepsilon$, is 10 . This means that the markup would be $11.11 \%$ over marginal cost if prices were flexible. Hall [1988] argues for much higher markups, whereas Basu and Fernald [1997] argue for somewhat lower markups. Our choice of $\varepsilon=10$ is representative of other recent work on monopolistically competitive macroeconomic models; for example, Rotemberg and Woodford [1999] use $\varepsilon=7.88$. We also explore the implications of a lower elasticity of demand which implies a higher markup.

\subsection{Distribution of price-setters}

A key aspect of our economy is the extent of exogenously imposed price stickiness. We use a distribution suggested by Wolman [1999], which has the following features. First, it implies that firms expect a newly set price to remain in effect for five quarters. That is: the expected duration of a price chosen at $t$, which is $\alpha_{1} 1+\left(1-\alpha_{1}\right) \alpha_{2} 2+\left(1-\alpha_{1}\right)\left(1-\alpha_{2}\right) \alpha_{3} 3+\ldots$ is equal to 5 . This estimate is consistent with the recent empirical work on aggregate price adjustment dynamics by Gali and Gertler [1999] and Sbordone [2002]. Second, rather than assuming a constant hazard $\alpha_{i}=\alpha$ as in the Calvo [1983] model, our weights involve an increasing hazard, which is consistent with available empirical evidence and recent work on models of state dependent pricing. The particular adjustment probabilities $\alpha_{i}$ and the associated distribution are given in Table 4; the average age of prices is $\sum_{j=0}^{J-1} j \omega_{j}=2.3$ for the benchmark parameterization. We explore some implications of assuming greater price flexibility below

\subsection{Credit costs and money demand}

Our model establishes a direct link between the distribution of credit costs and the demand for money, which was highlighted above in (35). Our money demand function,

$$
\frac{M_{t}}{\bar{P}_{t} c_{t}}=1-\xi_{t}=1-F\left(\frac{R_{t} c_{t}}{w_{t}}\right)
$$

embodies the negative effect of the interest rate and the positive effect of a scale variable - consumption expenditure - stressed in the transactions models of Baumol [1952] and Tobin [1956] as well as the positive effect of the wage rate stressed by Dutton and Gramm [1973]. That is, the fraction of goods purchased with credit is higher when the interest cost $R c$ is greater or when the wage rate $w$ is lower: the ratio $R c / w$ is the time value of interest foregone by holding money to buy consumption. 


\subsubsection{Estimating the demand for money}

We use the following procedure to estimate the demand for money. First, we posit that the distribution of credit costs is of the following "generalized beta" form:

$$
F(x)=\underline{\xi}+\bar{\xi} B\left(\frac{x}{\kappa} ; b_{1}, b_{2}\right)
$$

for $0<x \leq \kappa$. The basic building block of this distribution is the beta distribution, $y=B\left(z ; b_{1}, b_{2}\right)$, which maps from the unit interval for $z$ into the unit interval for $y$. It is a flexible functional form in that the parameters $b_{1}, b_{2}$ can be used to approximate a wide range of distributions. ${ }^{19}$ In the general expression (45), we allow for the standard beta distribution's independent variable to be replaced by $x / \kappa$, which essentially changes the support of the distribution of costs to $(0, \kappa)$. In addition, we make it possible for some goods to be pure cash or pure credit goods: $\underline{\xi}$ is a mass point at zero credit costs, allowing for the possibility that there are some goods that will always be purchased with credit; $\bar{\xi} \leq 1-\underline{\xi}$ similarly allows for goods for which money will always be used.

We use quarterly economic data to construct empirical analogues to our model's variables: a measure of the nominal stock of currency; a measure of nominal consumption expenditures per capita; a measure of the nominal interest rate; and a measure of the hourly nominal wage rate. ${ }^{20}$ The ratios $\frac{M_{t}}{\bar{P}_{t} c_{t}}$ and $\left(\frac{R_{t} c_{t}}{w_{t}}\right)$ are shown in Figure 1. ${ }^{21}$ Since there is not too much low frequency variation in $\left(\frac{c_{t}}{w_{t}}\right)$, the Figure mainly reflects the fact that the velocity of money and the nominal interest rate move together. Figure 1 highlights the fact that we explore two sample periods. First, we look at the sample 1948.1 through 1989.4. Our choice of the endpoint of this "long sample" is based on the evidence provided by Porter and Judson [1996] that an increasing portion of currency was held outside of the U.S. during the 1990s. The key feature of this longer sample period is that there is an initial interval of low nominal interest rates which makes the opportunity cost of money holding $(R c / w)$ quite low.

\footnotetext{
${ }^{19}$ See Casella and Berger [1990], pages 107-108, for a discussion of the beta distribution. The beta cdf takes the form $\left[\int_{0}^{x}(z)^{b_{1}-1}(1-z)^{b_{2}-1} d z\right] / \beta\left(b_{1}, b_{2}\right)$, where $\beta\left(b_{1}, b_{2}\right)=\Gamma\left(b_{1}\right) \Gamma\left(b_{2}\right) /\left[\Gamma\left(b_{1}+b_{2}\right)\right]$ is the beta function, which is in turn based on the gamma function as shown.

${ }^{20}$ The basic data used is a three month treasury bill rate; the FRB St. Louis's currency series; real personal consumption expenditures (billions of chained 1996 dollars); the personal consumption expenditures series chain-type price index $(1996=100)$; civilian noninstitutional population and average hourly earnings of production workers in manufacturing. The ratio $\mathrm{m} / \mathrm{c}$ is formed by taking the ratio of currency to nominal consumption expenditures, which is itself a product of real expenditures and the data. The ratio $R c / w$ is formed by multiplying the quarterly nominal treasury bill rate by nominal per capita consumption expenditures and then dividing by nominal average hourly earnings.

${ }^{21}$ The wage rate in the model is a wage per quarter, with the quantity of time normalized to one. The wage rate in the data is an hourly wage rate. Assuming that the time endowment per quarter is 16 hours per day, 7 days per week and 13 weeks per quarter, there are then 1456 hours per quarter. We therefore divide the data series $R c / w$ by this number of hours to get a measure that conforms to the theory.
} 
Second, we look at 1959.1-1989.4 since some analysts have argued that the earlier period is no longer relevant for U.S. money demand behavior.

Two estimated money demand functions are displayed in Figure 1, one for the shorter sample and one for the longer sample. Each money demand function is estimated by selecting the parameters $\left[\xi \xi \bar{\xi}, \kappa, b_{1}, b_{2}\right]$ so as to minimize the sum of squared deviations between the model and the data. ${ }^{22}$

\subsubsection{Implications of the money demand estimates.}

We stress three implications of the money demand estimates.

The estimated cost distribution: The parameter estimates over the two sample periods also imply distributions of credit costs, which are displayed in panel A of Figure 2. The first point to note is that the two costs cdfs are very similar for opportunity cost measures exceeding .002, as were the money demand functions in Figure 1. Below this point, the two functions differ substantially. The short sample period suggests that there are many goods (about two-thirds) that have zero credit costs. The longer sample period suggests that there are many more goods with small, but non-neglible transactions costs.

This figure anticipates the results presented below, by indicating not only the lowest interest rate data point as 'o' but also the optimal level of the nominal interest rate as '*'. For the short sample, the optimal nominal interest rate happens to be virtually identical to the minimum value in the sample, while for the longer sample the optimum is slightly above the minimum value.

The money demand elasticities: Given the cost distribution (45), there is not a single "money demand elasticity". But we can still compute the relevant elasticity at each point, producing panel B of Figure 2. For the long sample period, the money demand elasticity is less (in absolute value) than one-half and for the short sample period, it is less than one-third. The triangle in panel B indicates the money demand elasticity at the mean interest rate for the sample in question.

Bailey-Friedman calculations. Positive nominal interest rates lead individuals in this model to spend time in credit transactions activity that could be avoided if the nominal interest rate were zero. Given the estimated money demand function, with its associated distribution of credit costs, we can calculate this time cost as $h=\int_{0}^{(R c / w)} \nu d F(\nu)$, which is the area under the inverse money demand function. ${ }^{23}$ If all goods were purchased with credit, the short (long) sample money demand

\footnotetext{
${ }^{22}$ The nonlinear regression chooses the five parameters to minimize the sum of squared errors, $\frac{1}{T} \sum_{t=1}^{T}\left[\frac{M_{t}}{\bar{P}_{t} c_{t}}-\left(1-F\left(x_{t}\right)\right)\right]^{2}$ with $x_{t}=\left(\frac{R_{t} c_{t}}{w_{t}}\right)$ and $F\left(x_{t}\right)=\underline{\xi}+\bar{\xi} B\left(\frac{x_{t}}{\kappa} ; b_{1}, b_{2}\right)$. The point estimates for the short sample are $\left[\xi=.6394, \bar{\xi}=.1155, \kappa=.0127, b_{1}=2.8058, b_{2}=10.4455\right]$ and those for the long sample are $\left[\xi=.0658, \bar{\xi}=0.6859, \kappa=.0126, b_{1}=0.4824, b_{2}=7.1304\right]$.

${ }^{23}$ The "generalized beta" distribution makes this a particularly simple calculation because the truncated mean of a beta distribution is $\left[\int_{0}^{y} z(z)^{b_{1}-1}(1-z)^{b_{2}-1} d z\right] / \beta\left(b_{1}, b_{2}\right)=$ $\frac{\Gamma\left(b_{1}+1\right) \Gamma\left(b_{1}+b_{2}\right)}{\Gamma\left(b_{1}\right) \Gamma\left(b_{1}+b_{2}+1\right)} B\left(y ; b_{1}+1, b_{2}\right)$, so $h=\kappa \bar{\xi} \frac{\Gamma\left(b_{1}+1\right) \Gamma\left(b_{1}+b_{2}\right)}{\Gamma\left(b_{1}\right) \Gamma\left(b_{1}+b_{2}+1\right)} B\left(\frac{(R c / w)}{\kappa} ; b_{1}+1, b_{2}\right)$.
} 
estimates imply that individuals would spend approximately $0.03 \%(0.05 \%)$ of their time endowment in credit transactions. ${ }^{24}$ While our estimates are small relative to those which other researchers have found using aggregate U.S. data, we note that they are less unusual taken in the larger context of money demand studies. For example, using microeconomic data and a different methodology, Attanasio, Jappelli and Guiso [2002] also find relatively low welfare costs of inflation.

\section{Optimal policy in the long run}

There are two natural reference points for thinking about optimal policy in the long run. The first reference point is Friedman's [1969] celebrated conclusion that the nominal interest rate should be sufficiently close to zero so that the private and social costs of money-holding coincide. At this point, the economy minimizes the costs of decentralized exchange. The second reference point is an average rate of inflation of zero, which minimizes relative price distortions in steady state. In this section, we document the intuitive conclusion that the long-run inflation rate should be negative

- but not as negative as suggested by Friedman's analysis - when both sticky price and exchange frictions are present.

\subsection{The four distortions at zero inflation}

If there is zero inflation in the benchmark economy-which uses the credit cost technology with parameters set from the short sample estimates-then it is relatively easy to determine the levels of the four distortions. With zero inflation, the nominal and real interest rates are each equal to 2.93 percent per annum. The parameters of the credit cost technology imply that 65.6 percent of transactions are financed with credit $(\xi=.656)$ and that the ratio of real money to consumption is about 34 percent.

The markup is equal to that which prevails in the static monopoly problem, $\mu=$ $\frac{\varepsilon}{\varepsilon-1}=1 . \overline{11}$, so that price is roughly eleven percent higher than real marginal cost in the steady-state.

There are no relative price distortions - all firms are charging the same, unchanging price - so that $\delta=1$. Further, marginal relative price distortions are also small.

The wedge of monetary inefficiency is positive, but relatively small in this steady

\footnotetext{
${ }^{24}$ While this number may seem implausibly small to some readers, reference to Figures 1 and 2 helps understand why it is not given our transactions demand for money. As seen in Figure 1 , the largest amount of credit use - implying a rate of money to consumption of about $.25-$ begins to take place when the opportunity cost is about .005, which translates to an annualized interest rate of just under $10 \%$ as seen in Figure 2. With the estimated money demand over the short sample, the money demand curve cuts the axis at less than $m / c=.4$, implying an increase in $m / c$ of $.15=.4-.25$. Using a triangle to approximate the integral, we find that the approximate cost saving is $\frac{1}{2}(.005) * .15=.000375$ or $.0375 \%$.
} 
state. It is calculated from the above discussion as

$$
(1+(1-\xi) * R)=(1+(1-.656) * .0072)=1.0025,
$$

where the calculation of the wedge uses the quarterly nominal interest rate .0072 .

Time costs associated with use of credit are quite small, approximately $.004 \%$ of the time endowment. Recall that the maximal time costs - associated with using credit for all purchases - are about $0.03 \%$. At zero inflation, time spent on credit transactions involves only $14 \%$ of the maximum time that could be spent on credit transactions.

\subsection{The benchmark result on long-run inflation}

Even though the distortions associated with money demand are small at zero inflation, a monetary authority maximizing steady-state welfare would nonetheless choose a lower rate of inflation, for the reasons stressed by Friedman [1969]. When we solve the optimal policy problem for the benchmark model using the short-sample estimates displayed in Figure 1 above, we find that the asymptotic rate of inflation - the steady state under the optimal policy - is negative 76 basis points $(-0.76 \%$ at an annual rate). Given that we assume a steady state real interest rate of $2.93 \%$ percent (as determined by time preference), the long-run rate of nominal interest is $2.17 \%$.

This result raises two sets of questions. First, how do the four distortions isolated earlier in the paper contribute to this finding? Second, how do variations away from the benchmark parameter values affect the optimal long-run inflation rate? Each of these questions is addressed in Table 5 and in the discussion below.

\subsection{Optimal inflation with fewer distortions}

We now alter the monetary authority's problem - relative to the benchmark case by selectively eliminating one or more distortions. Table 5 shows the effect of various modifications of the mix of distortions. ${ }^{25}$

Why is disinflation desirable? Starting with the zero inflation steady state rate of inflation, the Table shows that both the wedge of monetary inefficiency and time costs play a role in reducing the inflation rate from zero to the benchmark level of $-.76 \%$. Table 5 shows that the wedge of monetary inefficiency has a moderate influence on the optimal long-run rate of inflation. If it is eliminated by itself, then the inflation rate rises from $-.76 \%$ to $-.54 \%$, so that the wedge accounts for almost $30 \%$ of the deviation from zero inflation. It also shows that if we only eliminate time costs, then the inflation rate rises further, from $-.76 \%$ to $-.28 \%$, so that time costs alone account for almost $65 \%$ of the deviation from the zero inflation position. ${ }^{26}$

\footnotetext{
${ }^{25}$ The table also presents results of the sensitivity analysis to be discussed below.

${ }^{26}$ Time costs and the wedge interact nonlinearly in determining the long run inflation rate. Therefore, adding up the contributions of the two effects in isolation does not yield the long run inflation
} 
Why is there less deflation than at the Friedman Rule? If prices are flexible, then the Friedman rule is optimal even though there is imperfect competition. In fact, Goodfriend [1997] notes that a positive markup makes the case stronger in a sense because the additional labor supply induced by declines in the wedge and time costs yield a social marginal product of labor which exceeds the real wage.

To evaluate why there is a benchmark rate of inflation of $-.76 \%$ per annum - as opposed to a Friedman rule level of $-2.93 \%$ per annum - it is necessary to eliminate variations in either the relative price distortion or the markup distortion. We suppose that the markup distortion is fixed at the zero inflation level, i.e., $\mu=\frac{\varepsilon-1}{\varepsilon}=1.11$. In this case, Table 5 shows that there is a slightly more negative rate of inflation than with a variable markup, a finding which is consistent with the facts that in this model, the average markup (i) is decreasing in the inflation rate near zero inflation; and (ii) does not respond importantly to variations in the inflation rate near zero inflation. The first fact explains why eliminating the distortion makes the optimal inflation rate more negative, since the monetary authority does not encounter an increasing markup in the modified problem as it lowers the inflation rate from a starting point of zero. The second fact explains why the effect is a small one quantitatively.

\subsection{Sensitivity Analysis}

We now explore the sensitivity of the steady-state rate of inflation to two aspects of the model. First, holding the parameters of money demand fixed at the benchmark levels, we explore the consequences of various structural features of the model. These results are presented in panel A of Table 5. Second, we discuss the long-run rate of inflation using the parameter estimates from the long sample. These results are presented in panel B of Table 5.

\subsubsection{Changing features of the model}

We explore the consequences of changing the degree of monopoly power and the extent of price stickiness.

Monopoly power: Decreasing the demand elasticity $(\varepsilon)$ to 6 leads to a larger deflation, $1.34 \%$ per year, because this lowers the costs of relative price distortions. The money demand distortions become relatively more important, pushing the optimum closer to the Friedman rule.

Price stickiness: we change the distribution of prices $(\omega)$ to $[0.3,0.28,0.25,0.2,0.1]$. With this distribution, the expected duration of a newly adjusted price is 3.8 quarters. The inflation rate in the long run under optimal policy is $-1.21 \%$. Optimal policy comes closer to the Friedman rule in this case because the relative price distortions associated with deviations from zero inflation are smaller the more flexible are prices.

rate from the benchmark case with both effects present. 


\subsubsection{Credit costs based on the long sample}

If we solve the optimal policy problem with the longer sample estimates, Panel B shows that there is much more deflation, reflecting the increased gains from substitution away from costly credit at low interest rates. The asymptotic rate of deflation is $-2.30 \%$, implying a nominal interest rate of only $0.63 \%$. The other structural features continue to affect the long-run inflation rate in the manner described above.

\section{Dynamics under optimal policy}

We now discuss the nature of the dynamic response of the macroeconomy under optimal policy. In any model with predetermined prices and monopoly distortions, the monetary authority will face an initial incentive to stimulate output. Our analysis does not concern these initial "start up" dynamics, but rather describes how the monetary authority will respond to shocks in the stochastic steady state which prevails when the economy has long been operating under an optimal policy. ${ }^{27}$ Instead, we study the nature of macroeconomic activity when shocks arise near the economy's steady state. In terms of economics, this approach involves considering how macroeconomic activity will respond when an optimal policy regime has been in place for some time. It is analogous to the real business cycle approach of studying the response of an economy to fluctuations near the steady-state path rather than concentrating on the economy's transitional dynamics.

The reference point for this discussion is the response of real quantities if prices are flexible and there are no money demand distortions. After discussing this case, we begin by studying optimal responses in a situation in which there are distortions from imperfect competition and sticky prices, but there are no money demand distortions. We contrast the effects of shocks to productivity and demand. We then turn to analyzing the effects of these same shocks when the monetary authority is confronted with money demand distortions as well.

\subsection{The real business cycle solution}

If intermediate goods firms have market power but can flexibly adjust their prices and if there are no money demand distortions, then the log-linear approximate dynamics of consumption and leisure are

$$
\begin{aligned}
\log \left(c_{t} / c\right) & =\frac{a}{a-g} \log \left(a_{t} / a\right)-\frac{g}{a-g} \log \left(g_{t} / g\right) \\
\log \left(l_{t} / l\right) & =\frac{g}{a-g}\left[\log \left(a_{t} / a\right)-\log \left(g_{t} / g\right)\right]
\end{aligned}
$$

${ }^{27}$ See King and Wolman [1999] for a description of the behavior of inflation and real activity during these initial periods, in a staggered pricing model similar to that considered in section 7.2 below. 
with the approximate dynamics of the real interest rate given by $r_{t}-r=E_{t}\left[\log \left(c_{t+1} / c\right)-\right.$ $\left.\log \left(c_{t} / c\right)\right]$, where $r=\beta^{-1}-1 .^{28}$ The consumption dynamics then imply that

$$
r_{t}-r=\frac{a}{a-g} E_{t}\left(\log \left(a_{t+1} / a\right)-\log \left(a_{t} / a\right)\right)-\frac{g}{a-g} E_{t}\left(\log \left(g_{t+1} / g\right)-\log \left(g_{t} / g\right)\right) .
$$

This real business cycle (RBC) solution is the benchmark for our subsequent analysis. We study impulse responses to productivity and government purchase shocks, under the assumption that each is first order autoregressive with a parameter $\rho$. Under this assumption, all of the macro variables in the $\mathrm{RBC}$ solution have simple solutions. For example, assuming that $\log \left(a_{t} / a\right)=\rho \log \left(a_{t-1} / a\right)+e_{t}^{a}$, the impulse response of the level of consumption to a productivity shock is just $\log \left(c_{t+j} / c\right)=\frac{a}{a-g} \rho^{j} e_{t}^{a}$ and that of the real interest rate is just $r_{t}-r=\frac{a}{a-g}(\rho-1) \rho^{j} e_{t}^{a}$. Since $\rho<1$, the real interest rate is low when the level of consumption is high, because consumption is expected to fall back to its stationary level.

\subsection{Optimal policy without money demand distortions}

In this section, we explore dynamic responses to productivity and government demand shocks in variants of our model with the money demand distortions eliminated, which is the case previously studied in King and Wolman [1999]. Here and below, our procedure is to make two uses of the first order conditions from the optimal policy problem. ${ }^{29}$ First, we solve these conditions for a stationary point, which is the long run limit that will occur under optimal policy. Second, we study the response to shocks near this stationary point, working also under the assumption that these shocks occur in the stationary distribution that obtains under optimal policy. As stressed above, we do so because we are interested in how the monetary authority will respond to shocks when it has long been operating under an optimal rule, rather than early in a monetary policy regime, when the monetary authority might exploit pre-determined prices. ${ }^{30}$

Without money demand distortions, the long run limit involves a zero inflation steady state. One focal point of our discussion, here and below, is on the response of the price level to our two shocks under optimal policy.

\footnotetext{
${ }^{28}$ Derivation of approximate dynamics is facilitated by recognizing that without money demand or relative price distortions, our model is governed by $c_{t}+g_{t}=a_{t}\left(1-l_{t}\right), w_{t}=\psi a_{t}$ with $\psi=\frac{\varepsilon-1}{\varepsilon}$ and $w_{t} D_{1} u\left(c_{t}, l_{t}\right)=D_{2} u\left(c_{t}, l_{t}\right)$. With $u(c, l)=\log (c)+\theta \log (l)$, there is an exact closed form solution $c_{t}=\frac{\psi}{\psi+\theta}\left(a_{t}-g_{t}\right)$ and $l_{t}=\frac{\theta}{\psi+\theta}\left(\frac{a_{t}-g_{t}}{a_{t}}\right)$.

${ }^{29}$ Above, we wrote the planner's first order conditions as $0=E_{t}\left\{\mathbf{F}\left(\underline{Y}_{t+1}, \underline{Y}_{t}, \underline{X}_{t+1}, \underline{X}_{t}\right)\right\}$. The first step involves finding $0=\mathbf{F}(\underline{Y}, \underline{Y}, \underline{X}, \underline{X})$. The second step involves solving the linear rational expectations model near this stationary point.

${ }^{30}$ Technically, we set all lagged multipliers equal to their certainty steady state values before examining the economy's response to shocks.
} 


\subsubsection{Productivity shocks}

Figure 3 displays the response of economic activity under optimal policy when there are persistent variations in productivity (the autoregressive coefficient is set equal to $.95)$. For the purpose of discussing this figure and the others below, we use the RBC solution as the reference point. Optimal policy here is to exactly replicate the RBC solution for quantities and this involves holding the path of the price level exactly constant through time.

Turning to the details of the graph, it is constructed under the assumption that there are no government purchases in the steady state, so that consumption moves one-for-one with the productivity shock and labor is predicted to be constant. The level of the productivity shock is $1.0 \%$ and the expected growth rate of consumption at date 0 is then $(\rho-1)=-.05$. We state the real interest rate in annualized terms, so that the impact effect on the real and nominal interest rate is -.20 or a decline of 20 basis points relative to the steady state level of the rate.

In this setting, then, there is no Keynesian stabilization policy: the government does not choose to smooth out the fluctuations that would occur if prices were flexible, even though there are monopoly distortions present in the economy which make output inefficiently low. At the same time, in order to bring about this flexible price solution, it is necessary for policy to be activist. For example, if the interest rate is the policy instrument, then it must move with the underlying determinants of the real interest rate.

\subsubsection{Government purchase shocks}

Figure 4 displays the response of economic activity under optimal policy when there are persistent variations in government purchases (the autoregressive coefficient is again set equal to .95). In this setting, the response of economic activity deviates from the flexible price solution, in a manner that is particularly evident in the path of interest rates.

Under the RBC solution, the basic mechanism is that there is a persistent, but ultimately temporary, drain on the economy's resources. In response to this drain, the representative agent consumes fewer market goods and takes less leisure, so that work effort rises. The real interest rate again reflects the response of consumption growth: it rises because consumption is expected to grow back toward the steady state as the government purchase shock disappears.

Under optimal policy, this basic picture is overlaid with an initial interval during which labor input and consumption are reduced relative to the levels that would prevail if prices were flexible. There is an important sense in which this is counterintuitive from a traditional perspective on stabilization policy: the monetary authority works to increase the variability of consumption stemming from a real shock rather than mitigate it. Working with pre-set pricing model of the sort developed by Ireland [1996] and Adao, Correia and Teles [2001], Goodfriend and King [2001] argue that 
the key to understanding the effects of government purchases is to recognize that optimal policy selects a state contingent pattern of consumption taking into account its influence on the contingent claims price $\lambda(c, l)=D_{1} u(c, l)$. Relative to the RBC solution, the government will want to have less consumption when government purchases are high because this increases the contingent claims value of $g$, making it easier to satisfy the implementation constraint. Our staggered pricing model displays a similar incentive, but a dynamic one: the monetary authority wants to depress the consumption path to an extent while there are predetermined prices. In line with this, Figure 4 shows that the optimal plan involves consumption which is transitorily low relative to the RBC solution. Because consumption is expected to grow toward the $\mathrm{RBC}$ path in these periods, the real interest rate - which continues to be described by $r_{t}-r=E_{t}\left[\log \left(c_{t+1} / c\right)-\log \left(c_{t} / c\right)\right]$-is high relative to the RBC path. The magnitude of this interest rate variation is substantial relative to the $\mathrm{RBC}$ component, because there is a temporary initial consumption shortfall, which implies rapid growth.

In our setting, then, it is not desirable for the government to stabilize consumption in the face of government purchase shocks, even though it is feasible for it to do so. Rather, the optimal policy is to somewhat reinforce the negative effects that $g$ has on consumption, thus attenuating the effects on employment and output. But, since the implied movements in real marginal cost are temporary, they have little consequence for the path of the price level.

\subsection{Optimal policy in the benchmark model}

We now calculate the response of the economy to productivity and government demand shocks in the benchmark model, in which we restore the two monetary distortions discussed in section 6 . In each case, we find that the solutions involve some interest rate smoothing, in both real and nominal terms.

\subsubsection{Productivity shocks}

Figure 5 shows the response of the economy to a productivity shock. On impact, consumption is slightly lower than the $\mathrm{RBC}$ response and then subsequently exceeds this level very slightly. But small differences in consumption paths translate into larger differences in growth rates and interest rates: rather than falling by 20 basis

points on impact, the nominal and real interest rates decline by a good bit less (the nominal rate falls by 7 basis points and the real rate by 8 basis points).

The dynamic behavior of real and nominal interest rates is of some interest. The real interest rate is smoothed relative to the $\mathrm{RBC}$ solution, but only during the first few quarters, presumably because this is the interval when the effects of pre-existing prices are important for the trade-offs that the monetary authority faces. Afterwards, the real interest rate closely tracks the underlying real interest rate associated with the $\mathrm{RBC}$ response. There is a small amount of expected inflation, which makes the nominal interest rate even less responsive to the productivity shock than the real rate. 
Yet the total effect on the price level is very small: it is about $0.25 \%$ over fifteen quarters, while productivity is inducing a cumulative rise in consumption of about $11 \% .{ }^{31}$ Even though they are not exactly those of the flexible price solutions, the real responses are quite close, indicating that the monetary authority does not make much use of the leverage that it has over real activity to undertake stabilization policy.

The motivation for interest rate smoothing in this economy involves the money demand distortions, as a comparison of the results of this section with those of (7.2.1) above makes clear. More specifically, we have found that it is the time cost distortion, as opposed to the wedge of monetary inefficiency, which accounts for most of the interest rate smoothing. It is interesting to note that maximal time costs which seem to be quite small can motivate the monetary authority to deliver significant smoothing of nominal interest rates. On the other hand, this smoothing results in only small variations in the price level, so the costs in terms of relative price distortions are small. ${ }^{32}$

\subsubsection{Government purchases}

Figure 6 shows the response of economic activity to a change in government purchases in the benchmark model. In contrast to the analysis of section (7.2.2), the response of the economy under optimal policy now much more closely resembles that in the RBC benchmark. That previous analysis indicated that optimal policy sought to increase the variability of real and nominal interest rates in response to a government purchase shock, but this incentive is now curtailed by the effect of such interest rate changes on the monetary distortions, especially the time cost. More specifically, the interest rate smoothing motivation approximately cancels out the earlier effects, leading to outcomes that closely resemble the flexible price solution.

\subsection{Robustness}

In Figure 7, we summarize the interest rate and price level responses to productivity and demand shocks in the benchmark model in the left hand column; we record these same responses for a version of the model using the long-sample money demand estimates in the right hand column. While there are differences across shocks and money demand specifications, the Figure illustrates that the optimal policy responses involve very small variations in the price level. While real interest rate behavior under optimal policy can deviate somewhat from the RBC solution, significant deviations are transitory, lasting only a few periods.

\footnotetext{
${ }^{31}$ That is: the total effect on productivity over fifteen quarters is given by $\frac{1-(.95)^{16}}{1-.95}=11.2$ and over the infinite horizon it is given by $\frac{1}{1-.95}=20$.

${ }^{32}$ In ongoing research, we are exploring the determinants of interest rate smoothing using a dynamic version of the method of eliminating selective distortions. Woodford [1999] discusses optimal interest rate smoothing in a related model.
} 


\section{Summary and conclusions}

Optimal monetary policy depends on the nature of frictions present in the economy. In this analysis, we have described a modern monetary model which has a range of frictions - imperfect competition, sticky prices and the costly exchange of wealth for consumption - and explored the nature of economic activity under optimal monetary policy. We initially developed a recursive equilibrium for a model economy with these three frictions. We then described how to calculate optimal allocations using the approach pioneered by Ramsey [1927], but also placed this analysis in recursive form. To derive quantitative results, we estimated a model of money demand, which determined the extent of transactions cost-savings, and we calibrated other aspects of the model in ways consistent with much recent research on imperfect competition and sticky prices.

As suggested by Friedman [1969], we found that deflation was one feature of an optimal monetary policy regime. The extent of this deflation was small (about $0.75 \%$ ) if we used estimates of money demand based on a sample that focused on post 1950 observations. It was larger (about 2.3\%) if we used estimates of money demand based on a longer sample that included earlier observations when interest rates and velocity were both low. However, because of the presence of relative price distortions that are increasing in the rate of inflation or deflation, it is not optimal to set the nominal rate equal to zero.

We studied the dynamic responses of economic activity under optimal policy to productivity and government purchase shocks, using three different assumptions about money demand. These dynamic responses are anchored by the dynamics of the underlying real business cycle model, so that real activity under optimal monetary policy always generally resembles these RBC solutions. At the same time, depending on the nature of the shocks and the details of money demand, there can be interesting departures of real interest rates and real activity from their counterparts in the real business cycle model. Yet, in all cases, optimal monetary policy involves very little "base drift" in the path of the price level, relative to the deflationary steady state path. 


\section{References}

[1] Adao, Bernardino, Isabel Correia and Pedro Teles, (2001), "Gaps and Triangles," Working Paper 2001-13, Federal Reserve Bank of Chicago.

[2] Attanasio, Orazio P., Luigi Guiso and Tullio Jappelli (2002), "The demand for money, financial innovation and the welfare cost of inflation: An analysis with household data" Journal of Political Economy 110 (2): 317 - 351.

[3] Bassetto, Marco, "Optimal Fiscal Policy with Heterogenous Agents," http://www.econ.umn.edu/ bassetto/research/opttax/opttax.pdf.

[4] Basu, Susanto, and John G. Fernald (1997), "Returns to Scale in U.S. Production: Estimates and Implications," The Journal of Political Economy, 105(2), $249-283$.

[5] Baumol, William, (1952), "The Transactions Demand for Cash," Quarterly Journal of Economics, 67(4), 545-556.

[6] Benveniste, Lawrence and Jose Scheinkman (1979), "On the Differentiability of the Value Function in Dynamic Models of Economies," Econometrica 47, 727732 .

[7] Calvo, Guillermo A. (1983). "Staggered Prices in a Utility-Maximizing Framework", Journal of Monetary Economics, 12, 383-398.

[8] Casella, George and Roger L. Berger, (1990), Statistical Inference, Belmont, California: Duxbury Press.

[9] Chari, V.V. and Patrick J. Kehoe (1999), "Optimal Fiscal and Monetary Policy," Handbook of Macroeconomics, Vol. III, edited by John Taylor and Michael Woodford, Elsevier, 1999.

[10] Dotsey, Michael and Peter N. Ireland (1996), "The Welfare Cost of Inflation in General Equilibrium," Journal of Monetary Economics, 37(1), 29-47.

[11] Dotsey, Michael, Robert G. King, and Alexander L. Wolman (1999). "State Dependent Pricing and the General Equilibrium Dynamics of Money and Output", Quarterly Journal of Economics.

[12] Dupor, Bill (2002). "Optimal Monetary Policy with Nominal Rigidities," manuscript, http://finance.wharton.upenn.edu/ $\sim$ dupor/dice_apr02.pdf.

[13] Dutton, Dean S., and William P. Gramm (1973), "Transactions Costs, the Wage Rate, and the Demand for Money," American Economic Review, 63(4), 652-665. 
[14] Fisher, Irving (1896), "Appreciation and Interest," in Publications of the American Economic Association, volume XI. New York: Macmillan.

[15] Fisher, Irving (1911), The Purchasing Power of Money, New York, Macmillan.

[16] Fisher, Irving (1923). "The Business Cycle Largely a 'Dance of the Dollar", Journal of the American Statistical Association 18 (144), 1024-1028.

[17] Fisher, Irving (1930), The Theory of Interest, New York, Macmillan.

[18] Friedman, Milton (1969), "The Optimum Quantity of Money," in The Optimum Quantity of Money, and Other Essays, Aldine Publishing Company: Chicago.

[19] Gali, Jordi, and Mark Gertler (1999), "Inflation Dynamics: A Structural Econometric Analysis," Journal of Monetary Economics 44(2), 195-222.

[20] Goodfriend, Marvin (1997), "A Framework for the Analysis of Moderate Inflations," Journal of Monetary Economics 39(1), 45-65.

[21] Goodfriend, Marvin and Robert G. King (1997), "The New Neoclassical Synthesis and the Role of Monetary Policy," in Bernanke, Ben S. and Rotemberg, Julio J., eds. NBER macroeconomics annual 1997. Cambridge and London: MIT Press, 1997, pages 231-83.

[22] Goodfriend, Marvin and Robert G. King (2001), "The Case for Price Stability," in Why Price Stability? Proceedings of the ECB First ECB Central Banking Conference. Frankfurt European Central Bank, Frankfurt am Main, Germany 2001, pages.53-94. Available as NBER Working Paper 8423.

[23] Hall, Robert E. (1988), "The Relation Between Price and Marginal Cost in U.S. Industry," Journal of Political Economy 96, 921-947

[24] Ireland, Peter N. (1996), "The Role of Countercyclical Monetary Policy," Journal of Political Economy, 104,704-723.

[25] Keynes, John Maynard (1936), The General Theory of Employment, Interest and Money, reprinted as a Harbinger Edition (1964), Harcourt, Brace and Jovanovich.

[26] King, Robert G., and Alexander L. Wolman (1999), "What Should the Monetary Authority Do When Prices are Sticky?" in Taylor, John B., ed., Monetary Policy Rules, Chicago: University of Chicago Press, 349-398.

[27] King, Robert G., and Alexander L. Wolman (1996), "Inflation Targeting in a St. Louis Model of the 21st Century," Federal Reserve Bank of St. Louis Review, 78, 83-107. 
[28] Kydland, Finn, and Edward C. Prescott (1977), "Rules Rather than Discretion: the Inconsistentncy of Optimal Plans," Journal of Political Economy 85(3): 473491.

[29] Kydland, Finn, and Edward C. Prescott (1980), "Dynamic Optimal Taxation, Rational Expectations and Optimal Control," Journal of Economic Dynamics and Control 2: 79-91.

[30] Lacker, Jeffrey M., and Stacey Schreft (1996), "Money and Credit as Means of Payment," Journal of Monetary Economics, 38(1), 3-23.

[31] Levin, Andrew (1991), "The Macroeconomic Significance of Nominal Wage Contract Duration," University of California, San Diego Discussion Paper 91-08.

[32] Lucas, Robert E., Jr., (1980), "Equilibrium in a Pure Currency Economy," Economic Inquiry, 18(2), 203-220.

[33] Lucas, Robert E., Jr. (2000), "Inflation and Welfare," Econometrica 68(2), 247274.

[34] Lucas, Robert E. Jr., and Nancy L. Stokey (1983), "Optimal Fiscal and Monetary Policy in an Economy without Capital," Journal of Monetary Economics 12: 5593.

[35] Marcet, Albert and Ramon Marimon (1999), "Recursive Contracts," manuscript.

[36] McCallum, Bennett T, and Marvin S. Goodfriend (1988), "Theoretical Analysis of the Demand for Money," Federal Reserve Bank of Richmond Economic Review, $74(1), 16-24$.

[37] Porter, Richard D., and Ruth A. Judson (1996), "The Location of U.S. Currency: How Much Is Abroad?" Federal Reserve Bulletin 82(10), 883-903.

[38] Prescott, Edward C. (1987), "A Multiple Means-of-Payment Model," in Barnett, William A., and Singleton, Kenneth J. eds., New approaches to monetary economics, Cambridge; New York and Melbourne: Cambridge University Press, $42-51$.

[39] Ramsey, Frank P. (1927), "A Contribution to the Theory of Taxation," Economic Journal 37: 47-61.

[40] Rotemberg, Julio J., and Michael Woodford [1999], "Interest Rate Rules in an Estimated Sticky Price Model," in Taylor, John B., ed., Monetary Policy Rules, Chicago: University of Chicago Press, 57-119.

[41] Sbordone, Argia M. (2002), "Prices and Unit Labor Costs: A New Test of Price Stickiness," Journal of Monetary Economics, 49(2), 265-292. 
[42] Taylor, John B. (1980), "Aggregate Dynamics and Staggered Contracts," Journal of Political Economy, 88: 1-24.

[43] Taylor, John B. (1993), "Discretion Versus Policy Rules in Practice," CarnegieRochester Conference Series on Public Policy 39, 195-214.

[44] Tobin, James (1956), "The Interest Elasticity of the Transactions Demand for Cash," Review of Economics and Statistics, 38(3), 241-247.

[45] Wolman, Alexander L. (1999), "Sticky Prices, Marginal Cost and the Behavior of Inflation," Federal Reserve Bank of Richmond Economic Quarterly 85(4), 29-45.

[46] Woodford, Michael, (1995), "Comment on, 'The Quantitative Analytics of the Basic Neomonetarist Model"', Journal of Money, Credit, and Banking, 27, 12781289.

[47] Woodford, Michael (1999), "Optimal Monetary Policy Inertia," NBER Working Paper 7261. 
Table 1:

Standard Lagrangian for optimal policy problem ${ }^{33}$

$$
\begin{aligned}
\min _{\left\{\mathbf{\Lambda}_{t}\right\}_{t=0}^{\infty}\left\{\mathbf{d}_{t}\right\}_{t=0}^{\infty}} \mathbf{E}_{0}\left\{\sum _ { t = 0 } ^ { \infty } \beta ^ { t } \mathbf { E } _ { t } \left[u\left(c_{t}, l_{t}\right)\right.\right. & \\
& +\varphi_{t}\left(\frac{\lambda_{t}}{1+R_{t}}-\beta E_{t}\left(\frac{\lambda_{t+1}}{1+\pi_{t+1}}\right)\right) \\
& +\phi_{0, t}\left(\omega_{0} x\left(p_{0, t}, c_{t}, l_{t}, \lambda_{t}, g_{t}, a_{t}\right)+\beta E_{t} \chi_{1, t+1}\right) \\
& +\sum_{j=1}^{J-2} \phi_{j, t}\left(\omega_{j} x\left(p_{j, t}, c_{t}, l_{t}, \lambda_{t}, g_{t}, a_{t}\right)+\beta E_{t} \chi_{j+1, t+1}-\chi_{j t}\right) \\
& +\phi_{J-1, t}\left(\omega_{J} x\left(p_{J-1, t}, c_{t}, l_{t}, \lambda_{t}, g_{t}, a_{t}\right)-\chi_{J-1, t}\right) \\
& +\eta_{t}\left(a_{t} n\left(l_{t}, \xi_{t}\right)-\left(\sum_{j=0}^{J-1} \omega_{j} p_{j, t}^{-\varepsilon}\right)\left(c_{t}+g_{t}\right)\right) \\
& +\gamma_{t}\left(1-\left(\sum_{j=0}^{J-1} \omega_{j} p_{j, t}^{1-\varepsilon}\right)^{\frac{1}{1-\varepsilon}}\right) \\
& +\sum_{j=1}^{J-2} \zeta_{j, t}\left(\frac{p_{j-1, t-1}}{1+\pi_{t}}-p_{j t}\right) \\
& +\vartheta_{t}\left(D_{1} u\left(c_{t}, l_{t}\right)-\lambda_{t}\left(1+R_{t}\left(1-\xi_{t}\right)\right)\right) \\
& \left.\left.+\varrho_{t}\left[\lambda_{t} R_{t} c_{t}-D_{2} u\left(c_{t}, l_{t}\right) F^{-1}\left(\xi_{t}\right)\right]\right]\right\} \\
&
\end{aligned}
$$

${ }^{33}$ In this table, $\mathbf{d}_{t}=\left\{c_{t}, l_{t}, \xi_{t}, \lambda_{t},\left(p_{j, t}\right)_{j=0}^{J-1},\left(\chi_{j, t}\right)_{j=1}^{J-1}, R_{t}, \pi_{t}\right\}$ is a vector of decisions at date $t$. Further, $\boldsymbol{\Lambda}_{t}=\left\{\varphi_{t},\left(\phi_{j, t}\right)_{j=0}^{J-1}, \eta_{1 t}, \eta_{2 t},\left(\zeta_{j, t}\right)_{j=1}^{J-2}, \vartheta_{t}, \varrho_{t}\right\}$ is a vector of Lagrange multipliers chosen at $t$. 
Table 2:

An augmented Lagrangian for optimal policy problem ${ }^{34}$

$$
\begin{aligned}
& U^{*}\left(s_{-1}, \phi_{-1}, \varsigma_{0}\right) \\
& \min _{\left\{\Lambda_{t}\right\}_{t=0}^{\infty} \max _{\left\{\mathbf{d}_{t}\right\}_{t=0}^{\infty}} \mathbf{E}_{0}\left\{\sum _ { t = 0 } ^ { \infty } \beta ^ { t } \mathbf { E } _ { t } \left[u\left(c_{t}, l_{t}\right)\right.\right.} \\
&+\varphi_{t} \frac{\lambda_{t}}{1+R_{t}}-\varphi_{t-1} \frac{\lambda_{t}}{1+\pi_{t}} \\
&+ \sum_{j=0}^{J-1} \phi_{j, t} \omega_{j} x\left(p_{j, t}, c_{t}, l_{t}, \lambda_{t}, g_{t}, a_{t}\right) \\
&+\sum_{j=1}^{J-1}\left(\phi_{j-1, t-1}-\phi_{j t}\right) \chi_{j, t} \\
&+\eta_{t}\left(a_{t} n\left(l_{t}, \xi_{t}\right)-\left(\sum_{j=0}^{J-1} \omega_{j} p_{j, t}^{-\varepsilon}\right)\left(c_{t}+g_{t}\right)\right) \\
&+\gamma_{t}\left(1-\left(\sum_{j=0}^{J-1} \omega_{j} p_{j, t}^{1-\varepsilon}\right)^{\frac{1}{1-\varepsilon}}\right) \\
&+\sum_{j=1}^{J-2} \zeta_{j, t}\left(\frac{p_{j-1, t-1}}{1+\pi_{t}}-p_{j t}\right) \\
&+ \vartheta_{t}\left(D_{1} u\left(c_{t}, l_{t}\right)-\lambda_{t}\left(1+R_{t}\left(1-\xi_{t}\right)\right)\right) \\
&+\left.\left.\varrho_{t}\left(\lambda_{t} R_{t} c_{t}-D_{2} u\left(c_{t}, l_{t}\right) F^{-1}\left(\xi_{t}\right)\right)\right]\right\}
\end{aligned}
$$

${ }^{34}$ In this table, $\mathbf{d}_{t}=\left\{c_{t}, l_{t}, \xi_{t}, \lambda_{t},\left(p_{j, t}\right)_{j=0}^{J-1},\left(\chi_{j, t}\right)_{j=1}^{J-1}, R_{t}, \pi_{t}\right\}$ is a vector of decisions at date $t$. Further, $\boldsymbol{\Lambda}_{t}=\left\{\varphi_{t},\left(\phi_{j, t}\right)_{j=0}^{J-1}, \eta_{1 t}, \eta_{2 t},\left(\zeta_{j, t}\right)_{j=1}^{J-2}, \vartheta_{t}, \varrho_{t}\right\}$ is a vector of Lagrange multipliers chosen at $t$. 
Table 3:

Fully recursive form of optimal policy problem $^{35}$

$$
\begin{gathered}
U^{*}\left(s_{t-1}, \phi_{t-1}, \varsigma_{t}\right)= \\
\min _{\left\{\Lambda_{t}\right\}\left\{\mathbf{d}_{t}\right\}}\left\{u\left(c_{t}, l_{t}\right)+\beta E_{t} U^{*}\left(s_{t}, \phi_{t}, \varsigma_{t+1}\right)\right. \\
+\varphi_{t} \frac{\lambda_{t}}{1+R_{t}}-\varphi_{t-1} \frac{\lambda_{t}}{1+\pi_{t}} \\
+\sum_{j=0}^{J-1} \phi_{j, t} \omega_{j} x\left(p_{j, t}, c_{t}, l_{t}, \lambda_{t}, g_{t}, a_{t}\right) \\
+\sum_{j=1}^{J-1}\left[\phi_{j-1, t-1}-\phi_{j, t}\right] \chi_{j, t} \\
+\eta_{t}\left(a_{t} n\left(l_{t}, \xi_{t}\right)-\left(\sum_{j=0}^{J-1} \omega_{j} p_{j, t}^{-\varepsilon}\right)\left(c_{t}+g_{t}\right)\right) \\
+\gamma_{t}\left(1-\left(\sum_{j=0}^{J-1} \omega_{j} p_{j, t}^{1-\varepsilon}\right)^{\frac{1}{1-\varepsilon}}\right) \\
+\sum_{j=1}^{J-2} \zeta_{j, t}\left(\frac{p_{j-1, t-1}}{1+\pi_{t}}-p_{j t}\right) \\
+\vartheta_{t}\left[D_{1} u\left(c_{t}, l_{t}\right)-\lambda_{t}\left(1+R_{t}\left(1-\xi_{t}\right)\right)\right] \\
\left.+\varrho_{t}\left[\lambda_{t} R_{t} c_{t}-D_{2} u\left(c_{t}, l_{t}\right) F^{-1}\left(\xi_{t}\right)\right]\right\}
\end{gathered}
$$

${ }^{35}$ In this table, $\mathbf{d}_{t}=\left\{c_{t}, l_{t}, \xi_{t}, \lambda_{t},\left(p_{j, t}\right)_{j=0}^{J-1},\left(\chi_{j, t}\right)_{j=1}^{J-1}, R_{t}, \pi_{t}\right\}$ is a vector of decisions at date $t$. Further, $\boldsymbol{\Lambda}_{t}=\left\{\varphi_{t},\left(\phi_{j, t}\right)_{j=0}^{J-1}, \eta_{1 t}, \eta_{2 t},\left(\zeta_{j, t}\right)_{j=1}^{J-2}, \vartheta_{t}, \varrho_{t}\right\}$ is a vector of Lagrange multipliers chosen at $t$. 
Table 4:

Price adjustment probabilities

and the associated distribution weights

\begin{tabular}{||l|l|l|l|l|l|l|l|l||}
\hline \hline$\alpha_{1}$ & $\alpha_{2}$ & $\alpha_{3}$ & $\alpha_{4}$ & $\alpha_{5}$ & $\alpha_{6}$ & $\alpha_{7}$ & $\alpha_{8}$ & $\alpha_{9}$ \\
\hline 0.014 & 0.056 & 0.126 & 0.224 & 0.350 & 0.504 & 0.686 & 0.897 & 1 \\
\hline$\omega_{0}$ & $\omega_{1}$ & $\omega_{2}$ & $\omega_{3}$ & $\omega_{4}$ & $\omega_{5}$ & $\omega_{6}$ & $\omega_{7}$ & $\omega_{8}$ \\
\hline 0.198 & 0.195 & 0.184 & 0.161 & 0.125 & 0.081 & 0.040 & 0.013 & 0.001 \\
\hline \hline
\end{tabular}


Table 5:

Effect of eliminating various distortions

on the long-run optimal inflation rate ${ }^{36}$

A. Short-sample money demand specification

\begin{tabular}{|l|l||l|l|l|}
\hline \multirow{2}{*}{} & \multicolumn{2}{|c||}{ Benchmark } & \multicolumn{2}{|c|}{ Sensitivity Analysis } \\
& & $\begin{array}{c}\text { Decrease } \\
\text { Demand } \\
\text { Elasticity }\end{array}$ & Increase \\
& & & Price \\
& Eliminate & & -1.34 & -1.21 \\
\hline 1 & & -0.76 & -0.78 & -0.84 \\
\hline 2 & Wedge & -0.54 & -0.86 & -0.59 \\
\hline 3 & Time Costs & -0.28 & 0 & 0 \\
\hline 4 & Wedge, Time Costs & 0 & -1.48 & -1.27 \\
\hline 5 & Markup & -0.81 & & \\
\hline
\end{tabular}

\section{B. Long-sample money demand specification}

\begin{tabular}{|c|c|c|c|c|}
\hline & Eliminate & Benchmark & $\begin{array}{c}\text { Sensitivity } \\
\text { Decrease } \\
\text { Demand } \\
\text { Elasticity }\end{array}$ & $\begin{array}{l}\text { nalysis } \\
\text { Increase } \\
\text { Price } \\
\text { Flexibility }\end{array}$ \\
\hline 1 & & -2.30 & -2.84 & -2.80 \\
\hline 2 & Wedge & -2.03 & -2.53 & -2.61 \\
\hline 3 & Time Cost & -0.21 & -0.62 & -0.42 \\
\hline 4 & Wedge, time cost & 0 & 0 & 0 \\
\hline 5 & Markup & -2.41 & -2.93 & -2.82 \\
\hline
\end{tabular}

\footnotetext{
${ }^{36}$ The benchmark model is in row 1, i.e., all distortions are present; the wedge of monetary inefficiency is eliminated in row 2; shopping time costs are eliminated in row 3; and both forms of monetary distortion are eliminated in row 4 . In row 5 , the markup is fixed at the zero inflation level $\varepsilon /(\varepsilon-1)$. The columns are as follows: benchmark calibration discussed in section 5; (b) demand elasticity for the differentiated products set to 6 instead of 10;.(c) the distribution of firms $(\omega)$ is modified from that in table 1 to $\omega=0.3,0.28,0.25,0.2,0.10$. In this case, no firm goes more than five periods with the same price, and the expected duration of a price is 3.8 quarters instead of 5.0 quarters as in the benchmark case.
} 
Figure 1. Velocity and the opportunity cost of holding money

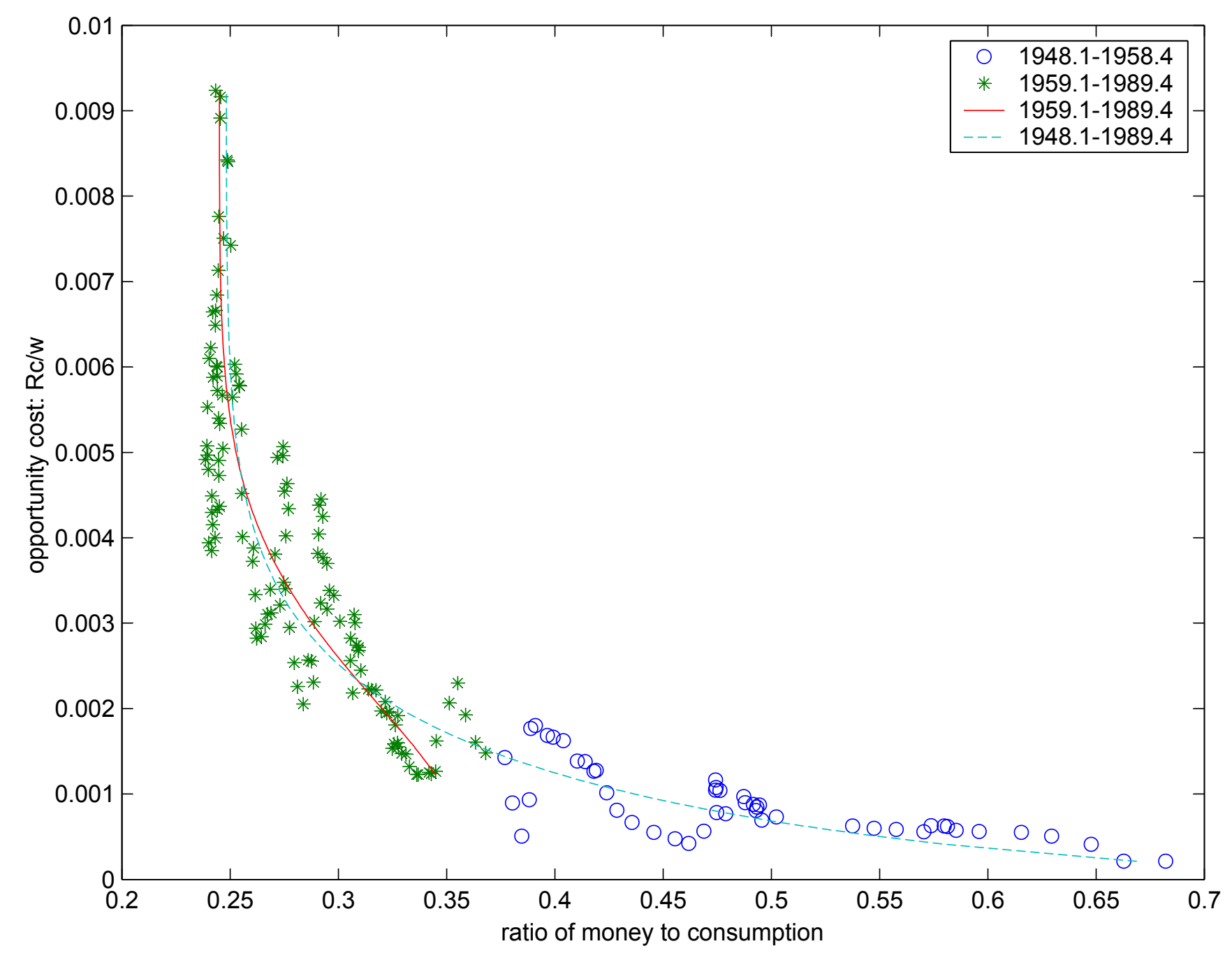


Figure 2. The Money Demand Estimates
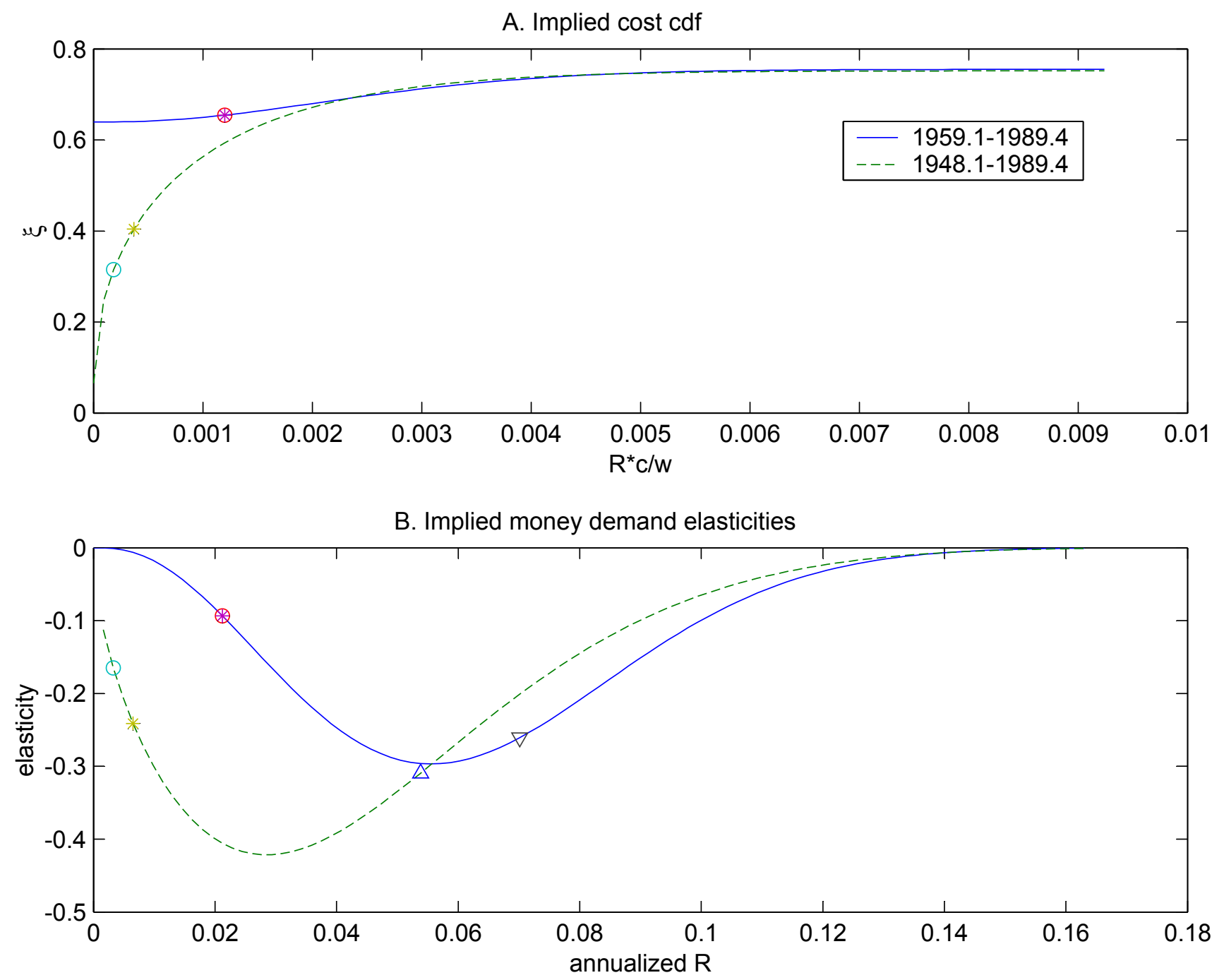
Figure 3. Model without money demand distortions

Response to a productivity shock under optimal policy

A. Consumption and the shock

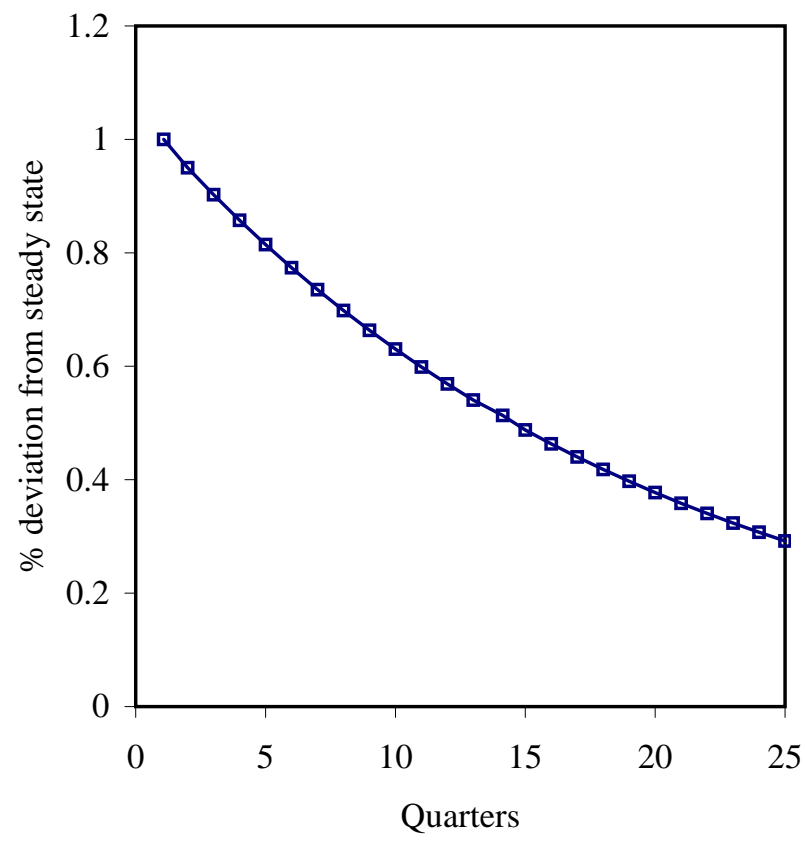

C. Rates: Nominal interest, real interest, and inflation

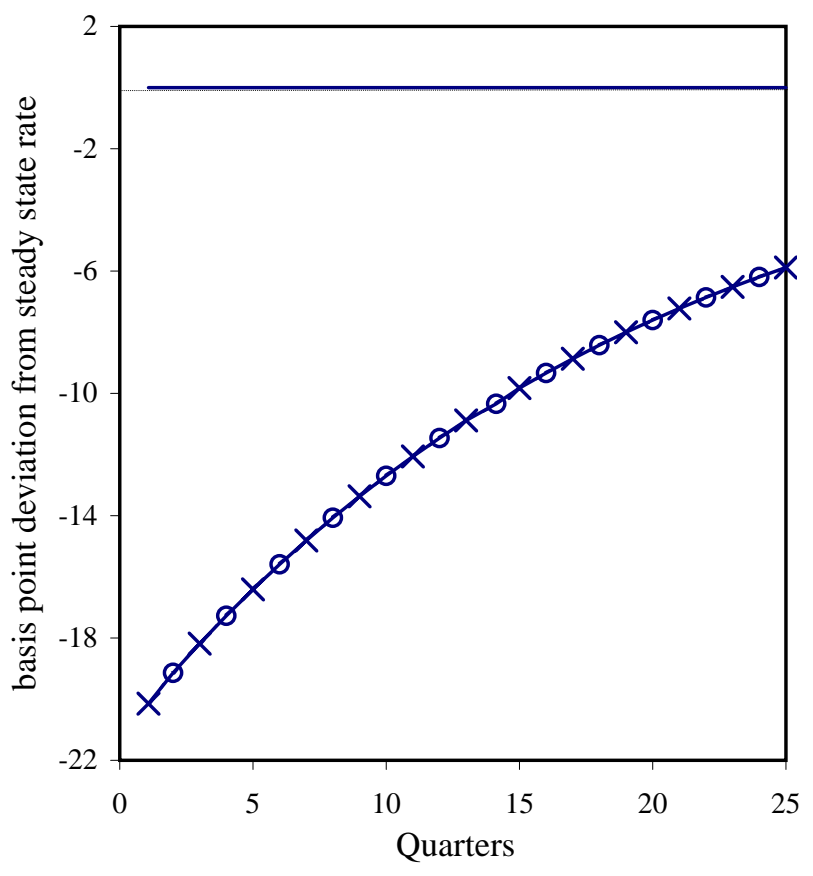

inflation rate (steady state $=0.0 \%$ )

- - $\times$ - - nominal interest rate (steady state $=2.93 \%$ )

-1 real interest rate (steady state $=2.93 \%$ )

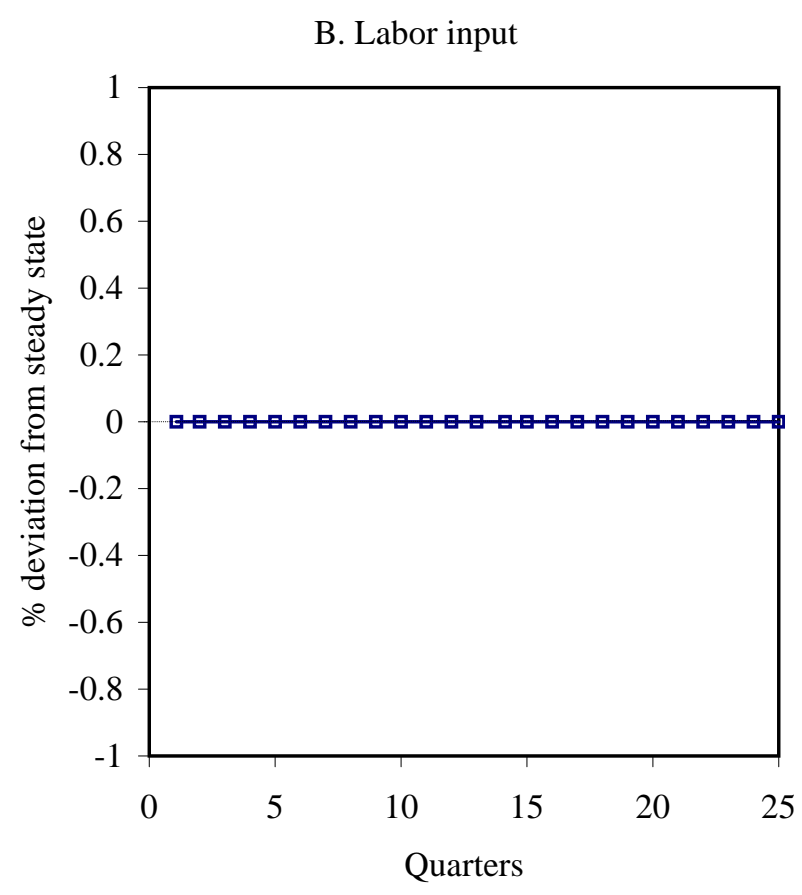

D. Price level

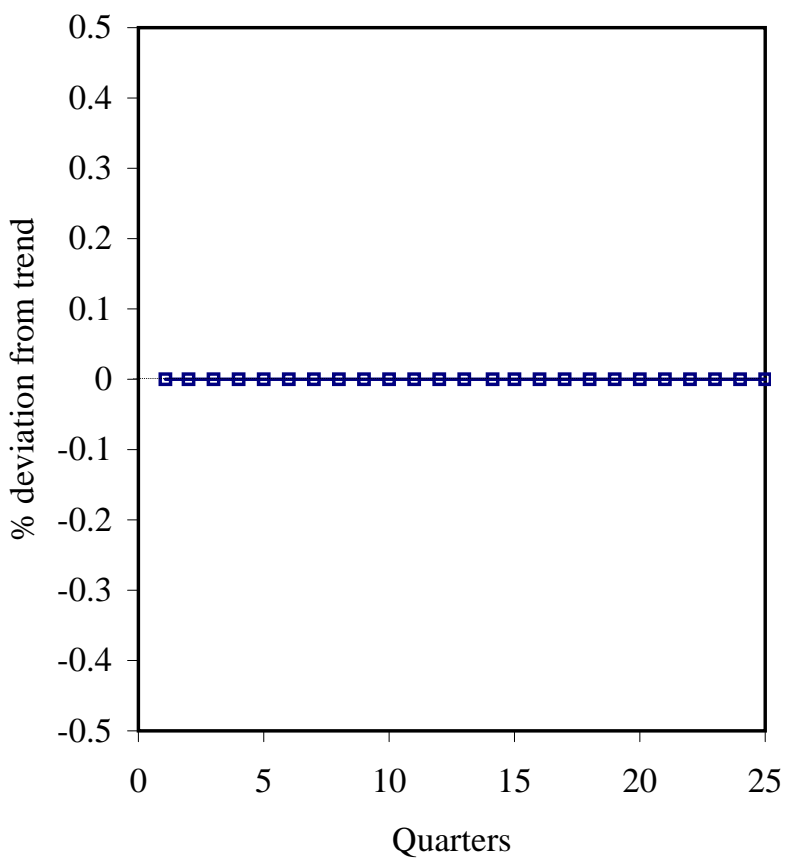


Figure 4. Model without money demand distortions Response to a government purchase shock under optimal policy

A. Consumption and the shock

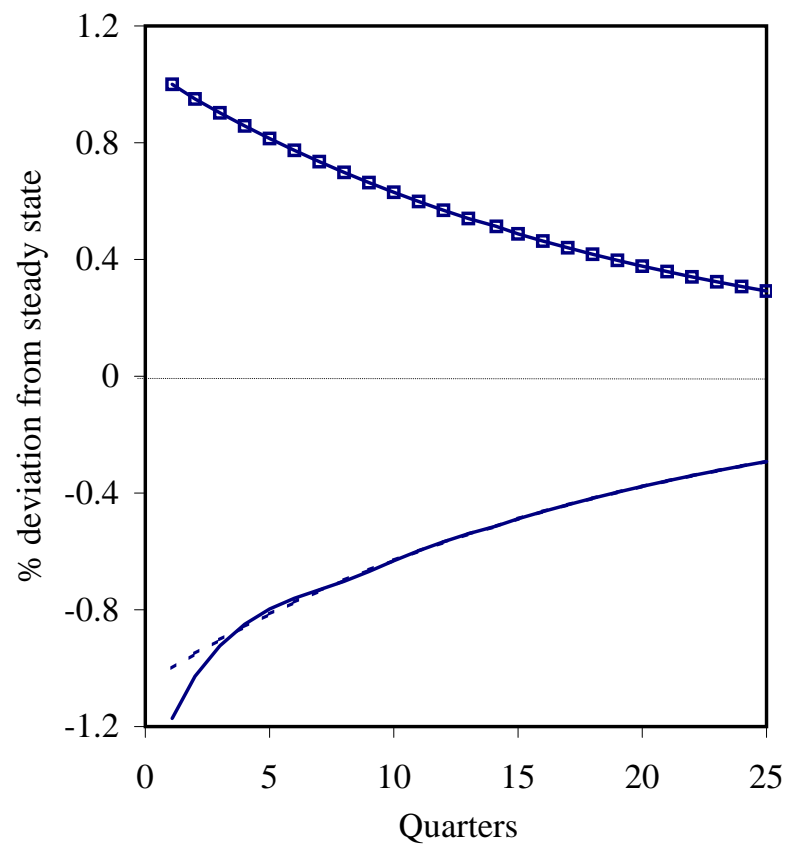

- consumption under optimal policy - . - consumption in RBC model $\longrightarrow$ path of the shock

C. Rates: Nominal interest, real interest, and inflation

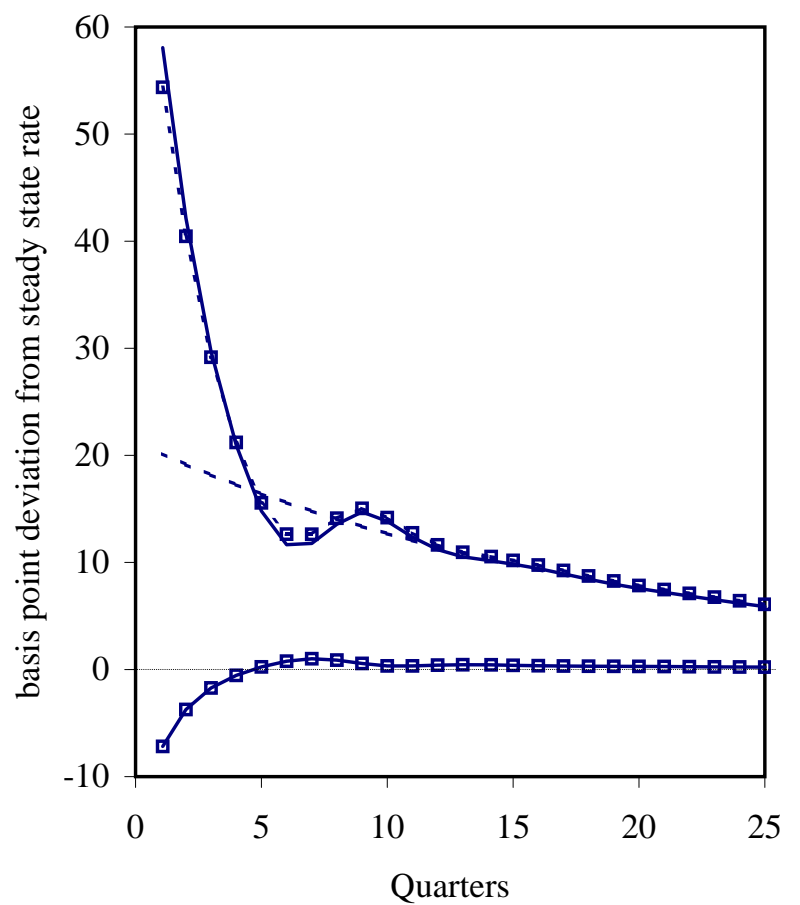

$\longrightarrow$ inflation rate (steady state $=0.0 \%$ )

- - $\mathbf{-}$ - - nominal interest rate (steady state $=2.93 \%$ )

- real interest rate (steady state $=2.93 \%$ )

... - real interest rate in RBC model
B. Labor input

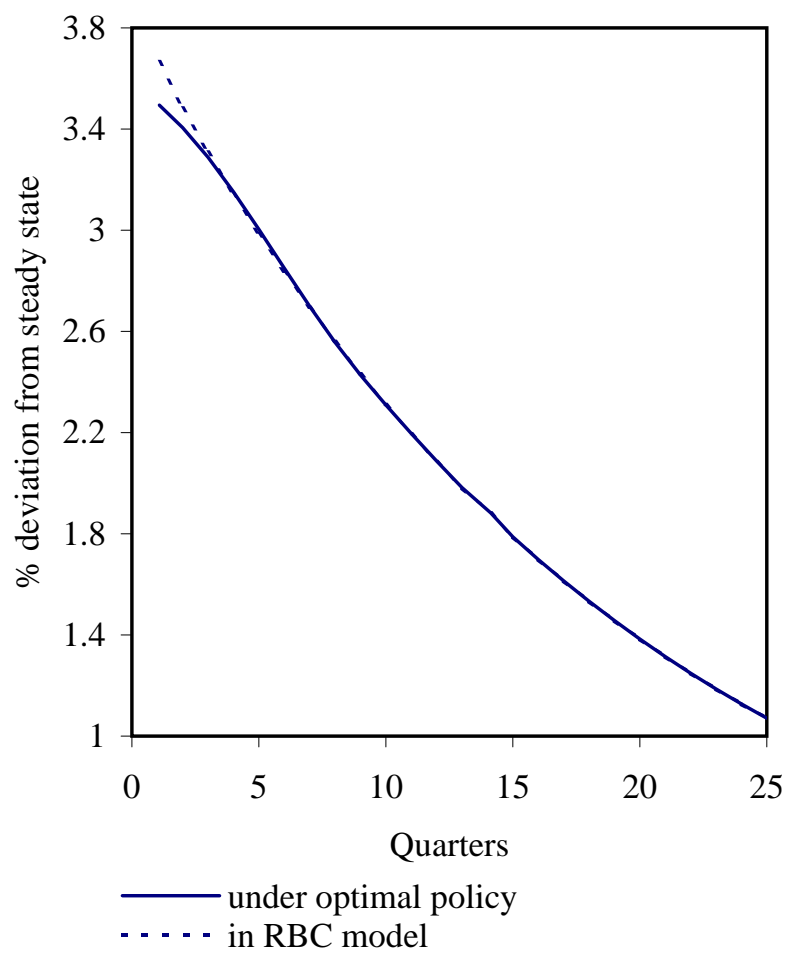

D. Price level

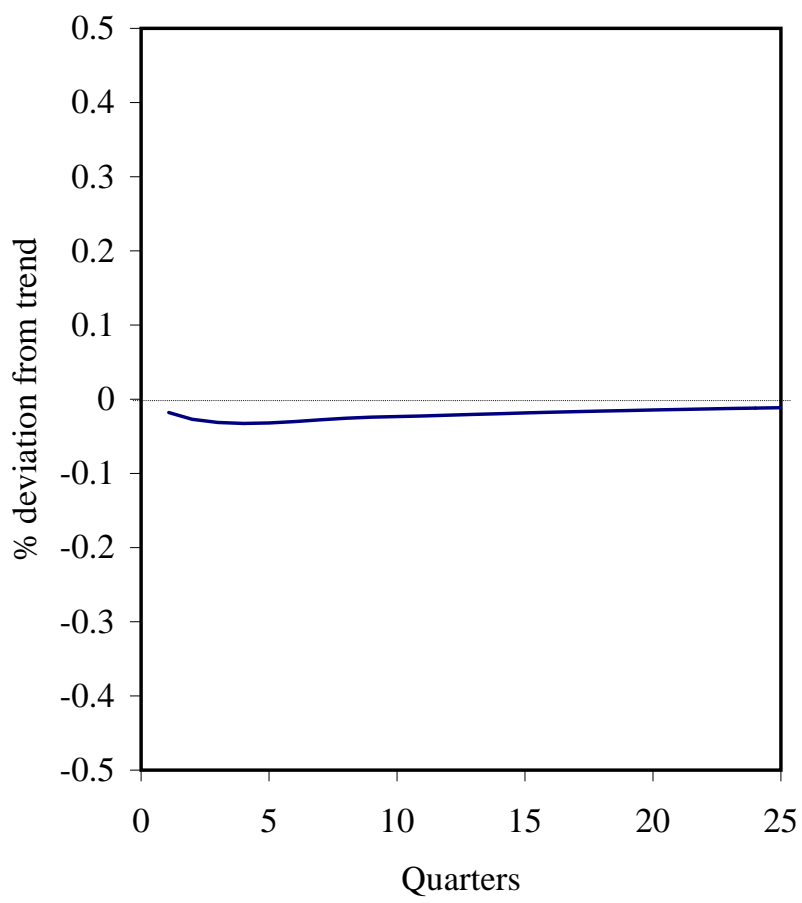


Figure 5. Full Model

Response to a productivity shock under optimal policy

A. Consumption and the shock

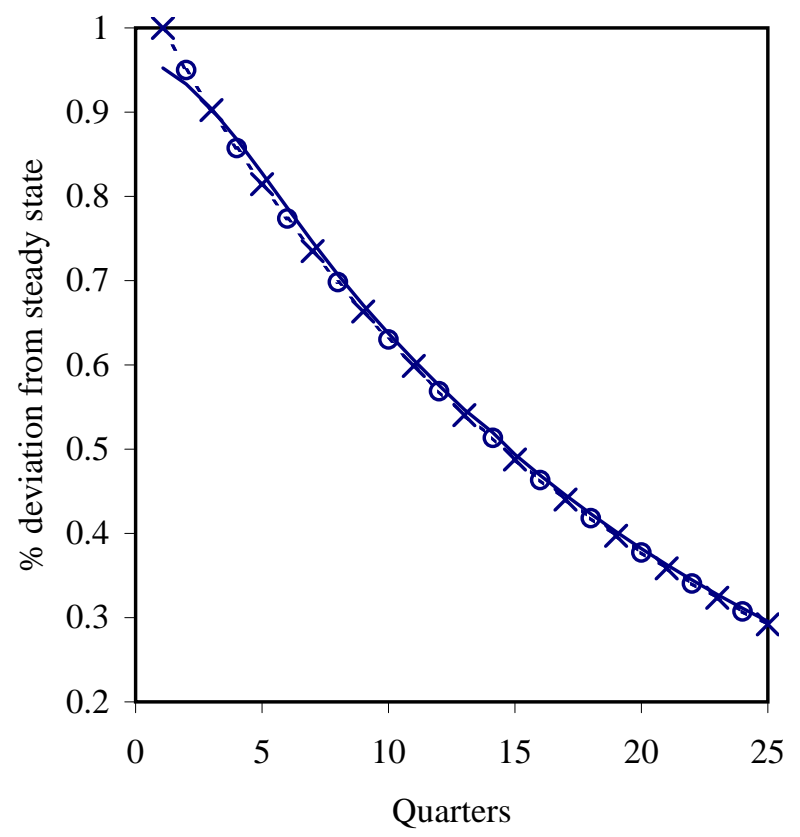

consumption under optimal policy

- - - path of the shock

- - - - consumption in RBC model

C. Rates: Nominal interest, real interest, and inflation

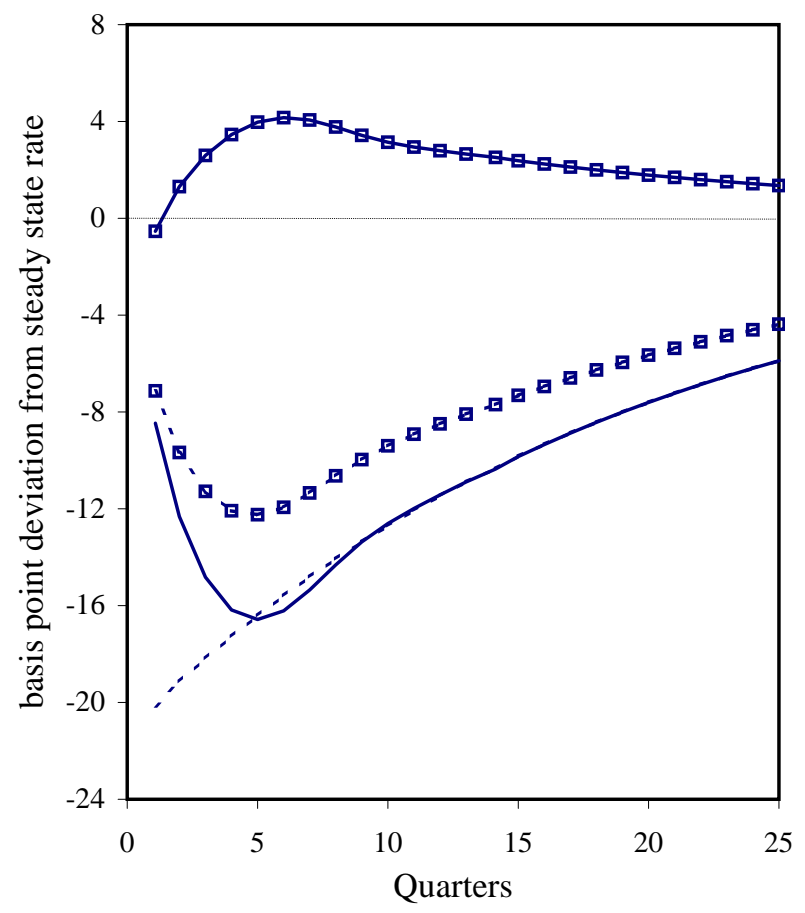

$\longrightarrow$ inflation rate (

- - - - nominal interest rate (steady state $=2.17 \%$ )

real interest rate (steady state $=2.93 \%$ )

. . - . - real interest rate in RBC model
B. Labor input

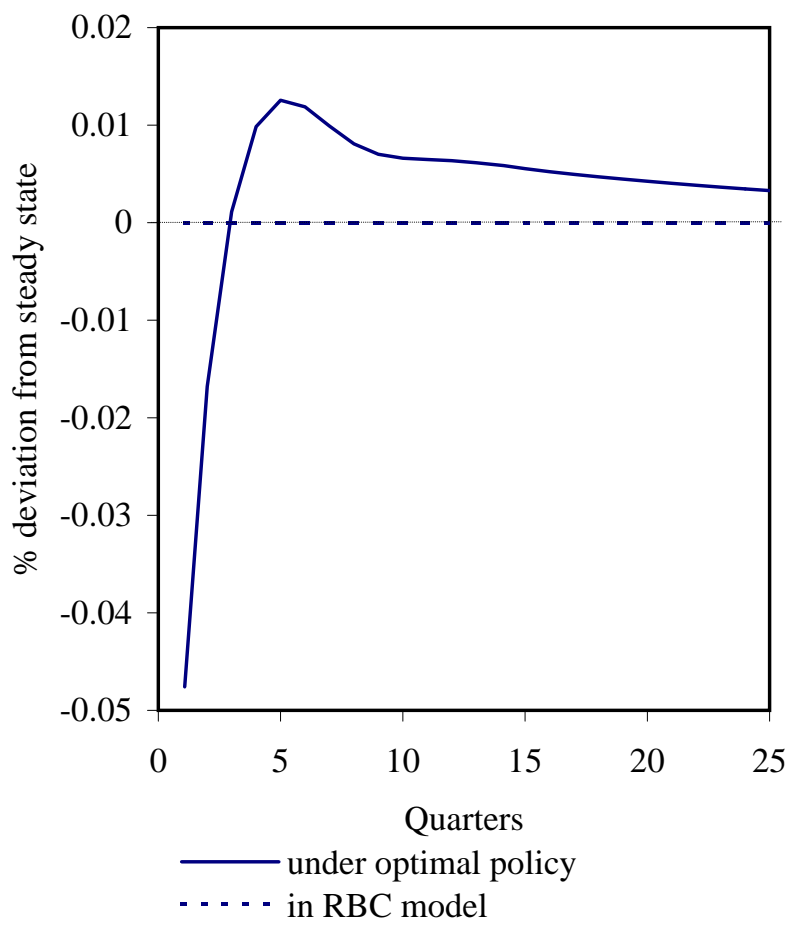

D. Price level

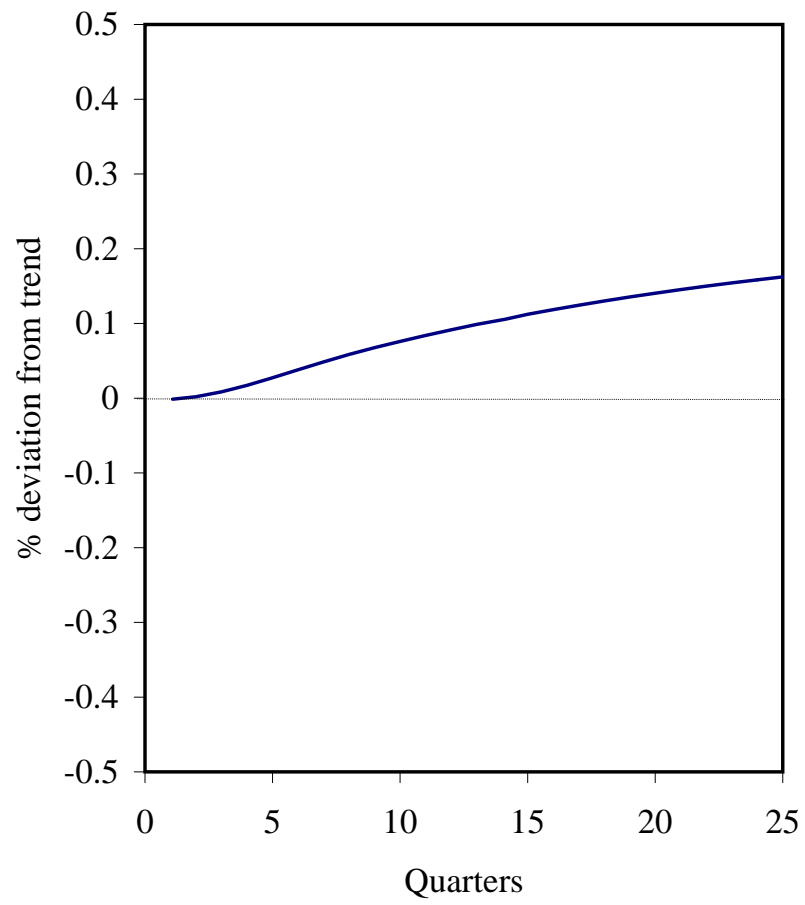


Figure 6. Full Model

Response to a government purchase shock under optimal policy

A. Consumption and the shock

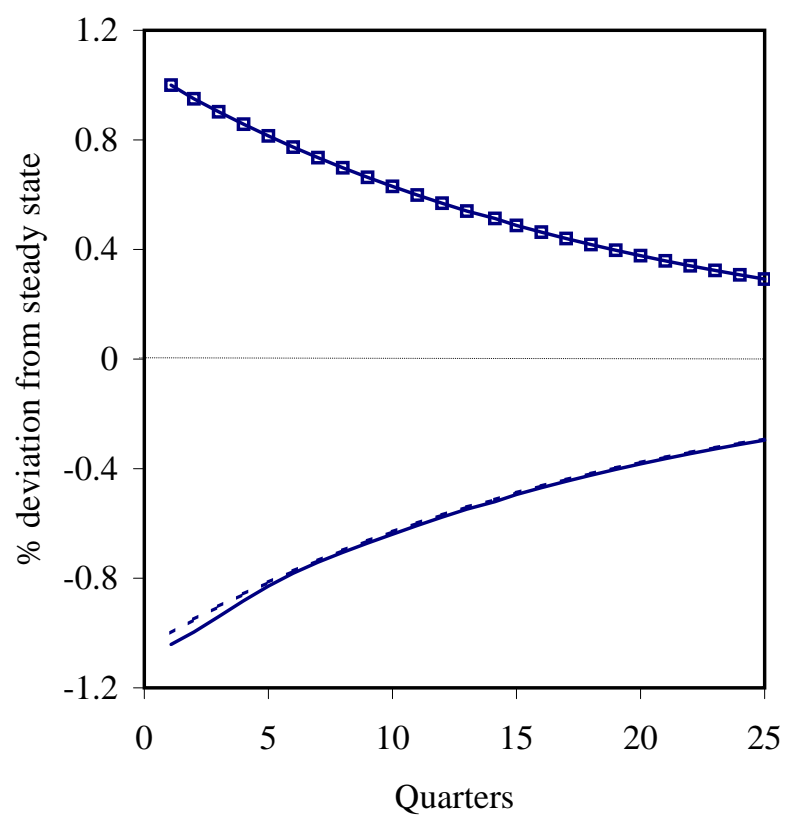

- consumption under optimal policy

- . - - consumption in RBC model

$\longrightarrow$ path of the shock

C. Rates: Nominal interest, real interest, and inflation

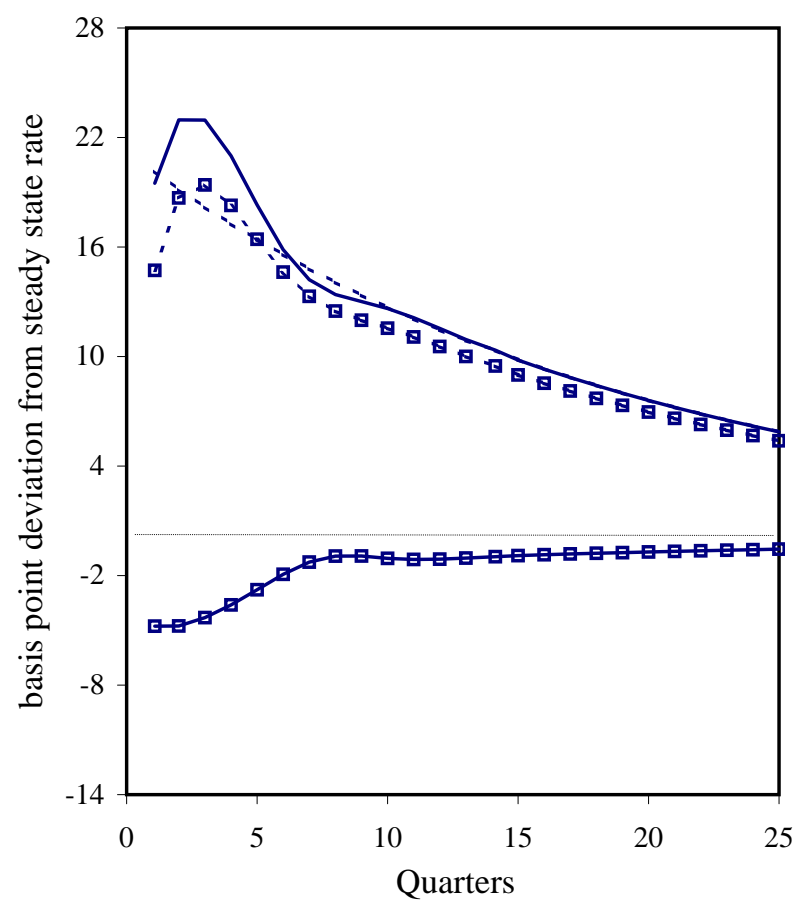

$\longrightarrow$ inflation rate (steady state $=-0.76 \%$ )

- - घ- - nominal interest rate (steady state $=2.17 \%$ )

real interest rate (

. . . - real interest rate in RBC model
B. Labor input

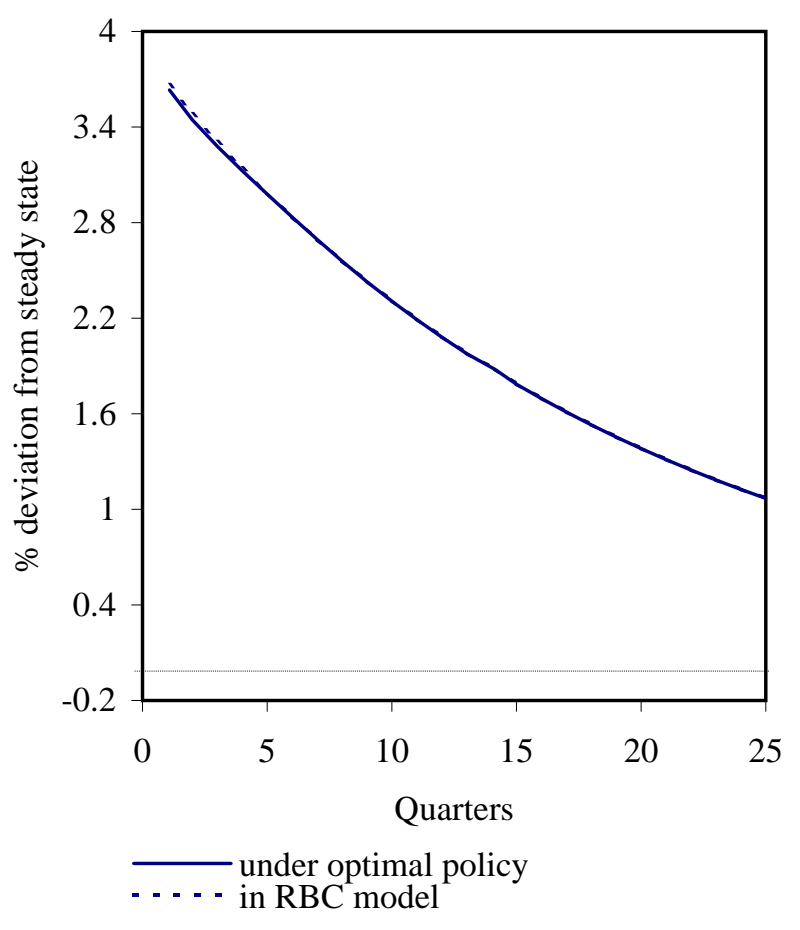

D. Price level

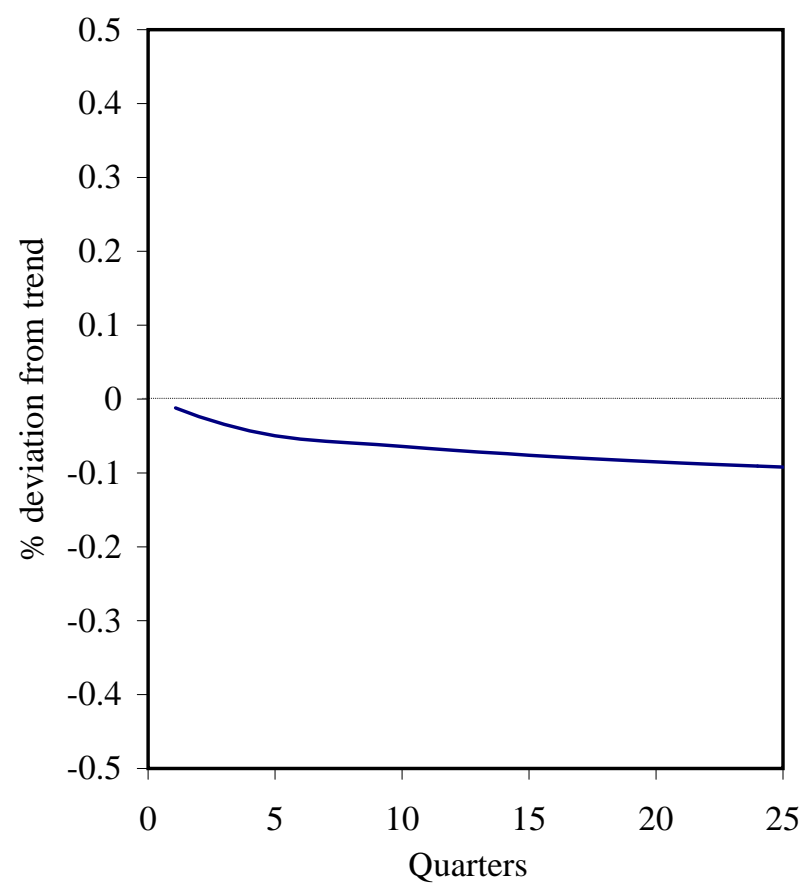




\section{Figure 7. Real Interest Rate and Price-level Behavior}

\section{A. Real Interest Rate Response to Productivity Shock}

A1. Short-sample money demand

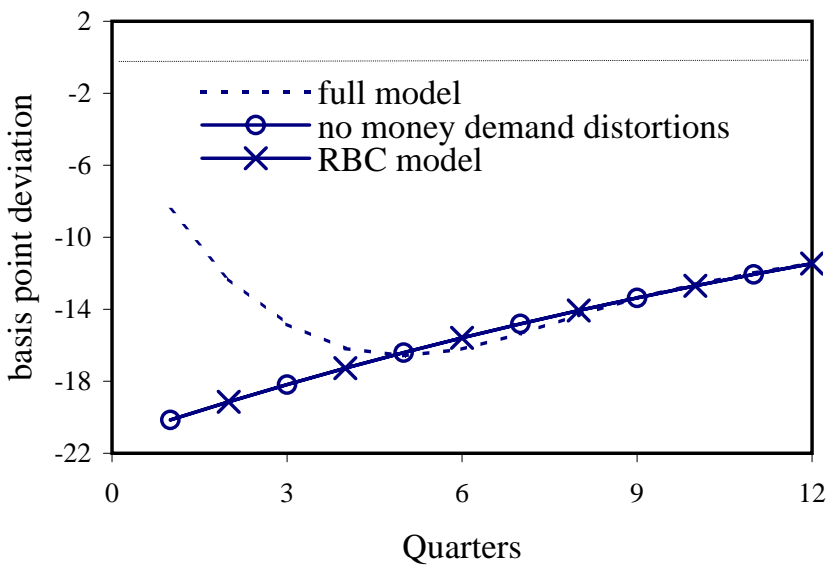

A2. Long-sample money demand

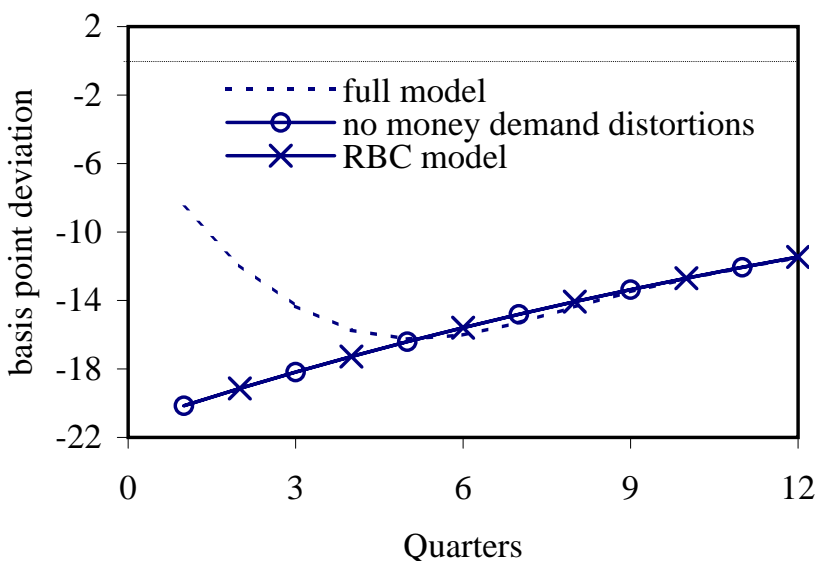

B. Real Interest Rate Response to Government Purchase Shock

B1. Short-sample money demand

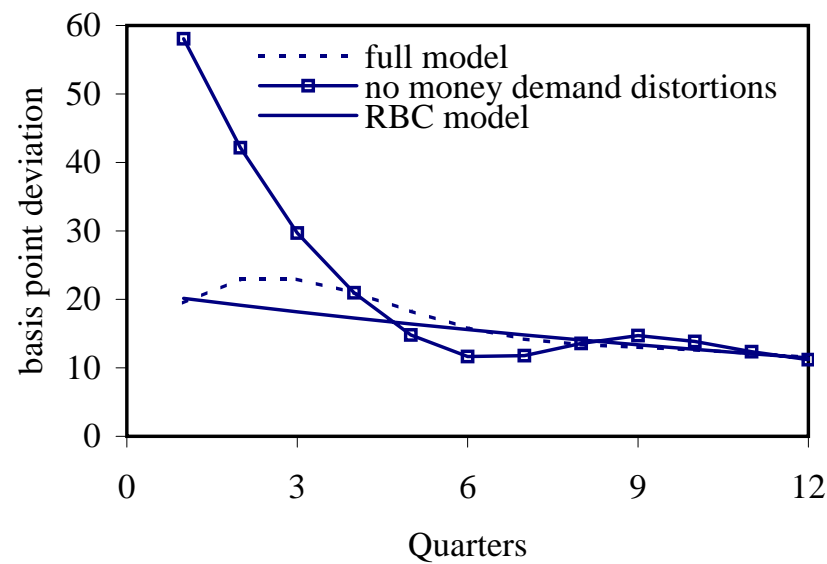

B2. Long-sample money demand

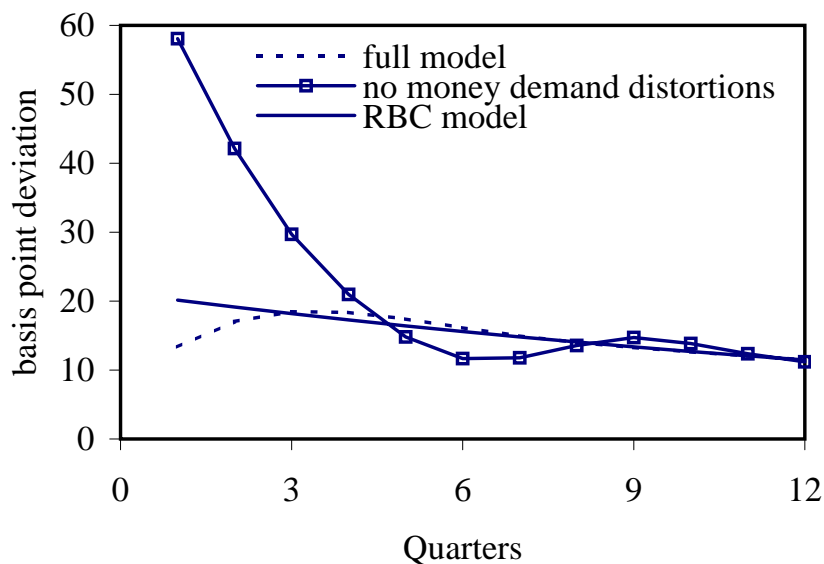

C. Price Level Responses to Productivity and Government Purchase Shocks

C1. Short-sample money demand

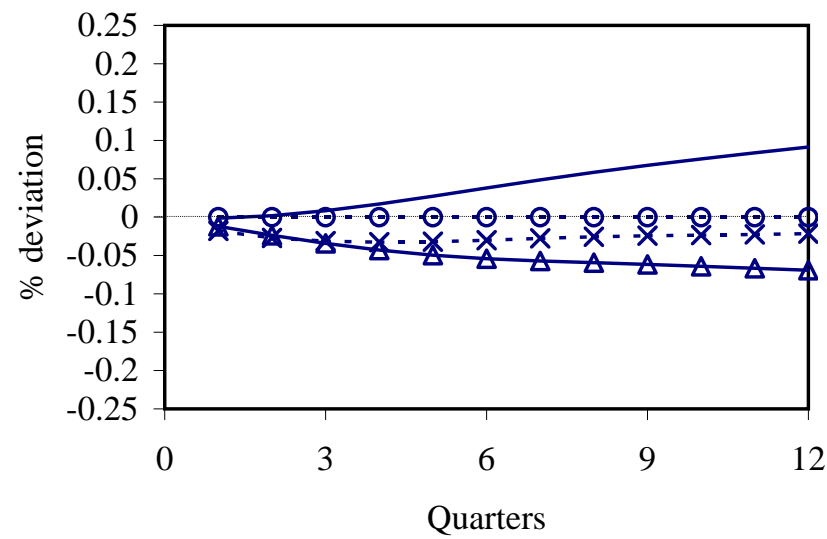

- productivity shock

- - - productivity shock, no money demand distortions

$\Delta-$ government purchase shock

- - $\Varangle-$ - govt. purchase shock, no money demand distortions
C2. Long-sample money demand

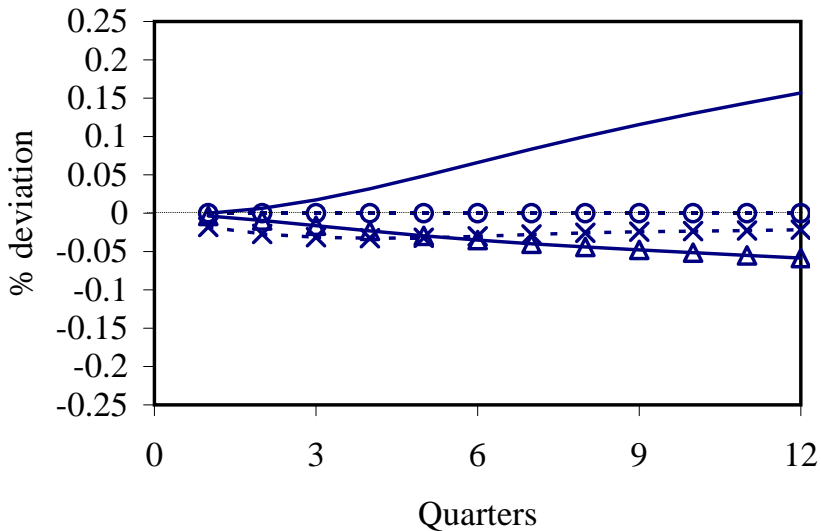

productivity shock

- - - - productivity shock, no money demand distortions $\Delta$ government purchase shock

- - - - govt. purchase shock, no money demand distortions 